\title{
NUEVAS PERSPECTIVAS DEL DERECHO NUCLEAR EN EUROPA Y EN ESPAÑA
}

\author{
Ángel RUIZ DE APODACA ESPINOSA \\ PRofesor Titular DE DERECHO ADMINISTRATIVO \\ UNIVERSIDAD DE NAVARRA
}

SUMARIO: I. Introducción. II. El Derecho Nuclear: riesgo, transparencia y participación. III. El Derecho Nuclear de la UE. Novedades. I. La Directiva de Seguridad Nuclear. 2. La Directiva de residuos radiactivos y gestión del combustible gastado. IV. El Derecho Nuclear en España. I. La Ley de energía nuclear de 1964 y el Reglamento de instalaciones nucleares de 1999. 2. Las autorizaciones de instalaciones nucleares y su naturaleza. 3. El Consejo de Seguridad Nuclear como Administración independiente. I. Regulación y naturaleza. 2. La necesaria transparencia en su actividad. 3. La potestad normativa del CSN. V. La reciente reforma del Ordenamiento Nuclear en España. I. La Ley 8/20II, de economía sostenible. 2. La Ley I2/20II, de responsabilidad civil por daños nucleares. 3. La Ley 8/20II, de infraestructuras críticas. 4. El Real Decreto I308/20II, sobre protección física de instalaciones y materiales nucleares. 5. Las nuevas exigencias de seguridad tras Fukushima. Nuevas pruebas de estrés demuestran que aún se puede mejorar en seguridad. VI. El marco normativo de la gestión de los residuos radiactivos y nucleares. I. La gestión en España. 2. El Plan gestor de residuos. 3. El actual procedimiento para la implantación de un almacén temporal centralizado (ATC).

RESUMEN: En este artículo se abordan las principales novedades normativas de Derecho nuclear a nivel comunitario y español principalmente tras el accidente de Fukushima. La decisión política y posterior procedimiento jurídico-autorizatorio acerca de las centrales nucleares debe basarse en análisis de riesgo sobre la seguridad y su impacto sobre la salud y el medio. En todo ello deben implementarse criterios de gobernanza no consistentes en una codecisión dado que la decisión siempre corresponde al Gobierno o Administración competente sino en la necesaria información y participación de los ciudadanos. En este artículo también se aborda el régimen jurídico de los residuos radiactivos, combustible gastado de las centrales nucleares y el actual procedimiento jurídico-administrativo para la implantación de un almacén temporal centralizado en España, decisión no exenta una vez más de conflicto social, político y territorial.

PALABRAS ClAVE: Energía nuclear, medio ambiente, gobernanza, riesgo, derecho público.

\section{NEW REgULATION ABOUT NUCLEAR LAW IN EUROPE AND SPAIN}

ABSTRACT: This article deals with the new European and Spanish legislation about nuclear power plants after Fukushima. The political decision about nuclear power plants and its authorization is based on procedures which entails analysis of various factors of security and environmental risk. In this decision it's necessary to ensure the governance, information and participation to prevent the concerns of the citizens. This study also examines the Spanish regulation of the spent nuclear fuel. At the moment, the Spanish Government has decided the construction of a central storage of spent fuel but the principal problem is the election of the location. The process of selecting an appropriated location is now under way. The information and the public participation are essential elements in both procedures of risk management to prevent social, political, environmental and legal conflicts.

KEYWORDS: Nuclear power, environment, governance, risk, public law 


\section{Introducción}

El presente artículo es el resultado actualizado de mi intervención en el X Seminario Permanente del Departamento de Derecho de la Universidad de La Rioja que tuvo lugar en abril de 20 II y en el que tuve el honor de participar como invitado para disertar sobre el nuevo panorama jurídico-normativo en el ámbito de la generación de energía nuclear. Los acontecimientos acaecidos en este año 20II han revolucionado de manera importante la percepción social y política de la energía nuclear y por ende su regulación jurídica, tanto a nivel comunitario europeo como a nivel estatal.

En este trabajo abordaré la energía nuclear y su perspectiva jurídica en un momento en que en España y en Europa se está produciendo un intenso debate sobre esta forma de generación de energía. Una opción energética no exenta de discusión política y social sobre sus riesgos. El reciente incidente derivado del terremoto y posterior tsunami en Japón sobre la central nuclear de Fukushima calificado con un nivel 7 en la escala INES, ha supuesto una vuelta más de tuerca sobre la cuestión de la energía nuclear en un momento en que parecía surgir una nueva apuesta por ella. Ya se habla claramente del «efecto Fukushima» en el replanteamiento de la política nuclear de todos los Estados.

Por otro lado, en España la discusión ya se había avivado con dos decisiones no exentas de polémica. La prórroga del permiso de explotación de la Central Nuclear de Santa María de Garoña y otra inmediata relacionada con uno de los principales problemas que plantea la sostenibilidad de esta opción: la gestión de los residuos radiactivos y particularmente el combustible gastado proveniente de las centrales nucleares en funcionamiento. A ello me refiero por la decisión sobre la ubicación territorial del Almacén Temporal Centralizado (ATC en lo sucesivo) de residuos radiactivos.

La energía nuclear constituye una de las fuentes de generación de energía más potentes pero que, sin duda, también entraña un mayor riesgo. Tras los accidentes de Three Mile Island en I978 y Chernobyl en I986, la regulación nuclear se ha basado principalmente en la búsqueda de la seguridad y a pesar de ello los recientes sucesos en la central de Fukushima en 20 II nos enseñan que la seguridad absoluta no existe.

En la UE los I4I reactores en funcionamiento proporcionan el 30\% de la energía consumida. De los 27 Estados miembros, en la actualidad i4 cuentan con reactores nucleares, Alemania (I7), Bélgica (7), Bulgaria (2), República Checa (6), Eslovaquia (4), Eslovenia (I), España (8), Finlandia (4), Francia (58), Hungría (4), Holanda (I), Reino Unido (I9), Rumania (2), y Suecia (Io).

Antes de Fukushima, la energía nuclear en Europa parecía renacer. En países como Suecia, tras 30 años de moratoria, el Gobierno había decidido recientemente mantener sus io centrales en funcionamiento y dotarlas de nuevos reactores. Italia suscribió un acuerdo de cooperación con Francia en febrero de 2009 , a pesar del referéndum que en I987 supuso el abandono de esta fuente de energía cerrando cuatro centrales. Un nuevo referéndum celebrado en junio de 20II sobre derogación de las nuevas normas que permitían la producción de energía nuclear ha supuesto el abandono de cualquier posibilidad de vuelta a la energía nuclear en el país transalpino'.

Alemania ha fijado 2022 como fecha límite para decir definitivamente adiós a esta forma de generación de energía y Bélgica en 2015 parará sus siete reactores nucleares en

* El presente trabajo se enmarca dentro del Proyecto de Investigación «Gobernanza en procedimientos administrativos de gestión del riesgo» financiado por el Ministerio de Ciencia e Innovación, DER- 2008/04I54.

${ }^{\mathrm{I}}$ Con una participación del 56\%, un 94\% votó a favor de la revocación de las leyes que permitían de nuevo la producción de energía nuclear en Italia. 
funcionamiento. Un vacío que a corto plazo no se podrá llenar sólo con renovables siendo necesaria una mayor participación del carbón con las consabidas consecuencias de emisiones contaminantes, lluvia ácida y potenciación del efecto invernadero. Estas son algunas de las manifestaciones de lo que se ha dado en llamar «efecto Fukushima». Otros países como Luxemburgo, Dinamarca, Noruega y Austria rechazan la energía nuclear, si bien cuentan con otros recursos energéticos.

En sentido contrario, en Reino Unido el Gobierno invitó el año pasado a varias empresas a levantar nuevos reactores nucleares a través de su Nuclear Policy Statement. Polonia, Bulgaria, Eslovaquia, Rumania y Lituania también tienen planes de construcción en distinto grado de desarrollo y en Finlandia se está a punto de concluir la construcción de una nueva central.

Como es sabido, las políticas de los Estados en relación con la energía nuclear se fijan en tres clases de opciones: los estados que cuentan abiertamente con un amplio programa nuclear, los estados que rechazan o prohíben el desarrollo nuclear y la mayoría que es lo que denominaríamos como Estados neutrales. La decisión es política y, frente a ella, el Derecho juega un papel secundario y, además, instrumental. El Derecho, por tanto, condiciona muy poco las grandes decisiones de política nuclear. Sin embargo, la asunción del riesgo nuclear sí condiciona el Derecho y en particular el Derecho Administrativo lo que contribuye a explicar algunas de las transformaciones que esta rama del Derecho viene experimentando en los últimos tiempos y que principalmente ha puesto de manifiesto el profesor Esteve Pardo (2009).

España por su parte cuenta con un parque de seis centrales nucleares ( 8 reactores) en operación con una potencia instalada de $7728 \mathrm{MW}(7,85 \% \text { del total })^{2}$, tras el cierre de la central de Vandellós I en 1989 y de José Cabrera en 2006. Tras la denominada moratoria nuclear confirmada mediante la Ley 40/1994, del sistema eléctrico nacional, se produjo la extinción de las autorizaciones otorgadas en España, no habiéndose proyectado ninguna nueva central nuclear mientras las existentes van agotando su vida de diseño.

\section{El Derecho Nuclear: riesgo, transparencia y participación}

La energía nuclear constituye un enorme factor de riesgo para el medio ambiente, la vida y la salud de las personas. Una vez más nos encontramos ante una situación de análisis de riesgo en el que ubicar en el fiel de la balanza la necesidad y beneficios de la generación de energía por un lado, y por otro los riesgos que de ello se derivan y en qué medida una sociedad desarrollada e informada está dispuesta a asumir. No hay ninguna energía sin riesgos, pero son cuestiones que cada sociedad tiene que sopesar. La decisión sobre una determinada instalación nuclear se basará en opciones, en la necesaria ponderación de riesgos, tanto la decisión primaria o política, como la ulterior de carácter jurídico residenciada en un procedimiento autorizatorio de gestión del riesgo.

El Derecho actual no impone ninguna de las opciones energéticas en liza, la decisión sobre la energía nuclear es puramente política, los poderes públicos gozan de entera libertad para configurar la política nuclear que estimen más conveniente en cada momento. Como señala Santamaría Arinas (2009, ro8), el Derecho juega un papel secundario e instrumental

${ }^{2}$ La Historia de las Centrales Nucleares en España puede resumirse en tres fases: las Centrales de primera generación en los 60 fueron: José Cabrera (Guadalajara), Vandellós I (Tarragona) ya clausuradas y Santa María de Garoña (Burgos), aún en funcionamiento. Las de $2^{\mathrm{a}}$ generación en los 70 fueron Almaraz I y II (Cáceres), Ascó I y II (Tarragona), Cofrentes (Valencia) y Lemóniz en Vizcaya ésta ultima no llegó a entrar en funcionamiento. Por último las centrales de $3^{\text {a }}$ generación tras la aprobación del PEN de I979 son las de Vandellós II (Tarragona), Trillo I (Guadalajara) y Valdecaballeros que tampoco llegó a entrar en funcionamiento. 
aunque a mi juicio fundamental una vez adoptada la previa decisión sobre todo a efectos de idoneidad de la ubicación y, sobre todo, exigencia de seguridad y responsabilidad.

La utilización de la energía nuclear para producir energía eléctrica en las centrales nucleares es una de las industrias más reguladas, con un mayor régimen de intervención, de control, de inspección y, en su caso, sanción.

La rama jurídica del Derecho nuclear ${ }^{3}$ se caracteriza como no puede ser de otra manera por un gran intervencionismo público y en consecuencia, sin perjuicio de su multidisciplinariedad podemos afirmar que se trata principalmente de Derecho Administrativo $^{4}$. Igualmente, el Derecho nuclear se caracteriza por su naturaleza técnica, internacional, evolutiva, intervencionista y globalizada que tiene por finalidad regular y disciplinar las actividades relacionadas con la energía nuclear de forma que se proteja adecuadamente el medio ambiente y la salud de las personas, y que emana de fuentes diversas, jerárquicamente dispares, y en ocasiones carentes de fuerza normativa vinculante (Morales Plaza 2009b, 526).

El Derecho de la energía nuclear es por tanto, una rama del Derecho que como otras muchas está trufada de ramificaciones técnicas y científicas.

La primera característica por obvia es la de su necesidad, cuanto mayores son los riesgos de una determinada actividad más necesaria es su regulación detallada y elaborada así como una estructura administrativa adecuada que controle su efectivo cumplimiento.

Otro aspecto destacable en el Derecho Nuclear lo constituye la gobernanza en la toma de decisiones relativas a instalaciones nucleares. Esto supone una necesaria transparencia de manera que estas decisiones no deben ser tomadas sólo por los políticos ni sólo por los científicos, sino por la sociedad en su conjunto sobre la base de una información que ha de ser comprensible, eludir academicismos y tecnicismos, ser temprana, veraz y desinteresada. El problema no radica sólo en las decisiones humanas que generan los riesgos, sino también en las decisiones humanas que los distribuyen, si bien es cierto que son muchos los que propugnan la máxima participación pública en las correspondientes tomas de decisión 5 .

El surgimiento de la evaluación del riesgo está ligado al desarrollo de la energía nuclear, que a su vez es también el origen de la problematización social y política del riesgo ${ }^{6}$. Esta necesaria ponderación en el caso de la generación de energía es clara. Hay riesgos asumibles o no y la decisión sobre si un determinado riesgo es asumible exige una previa ponderación ${ }^{7}$. No existe el riesgo cero.

Hay que preguntarse qué coste estamos dispuestos a pagar por la energía, por la seguridad y continuidad del suministro, qué costes ambientales estamos dispuestos a asumir y

\footnotetext{
${ }^{3}$ Sobre el régimen jurídico de la energía nuclear, es necesario destacar los siguientes estudios, algunos muy tempranos pero actuales en sus consideraciones como los de Martín- Retortillo, L. (1964); Tocino Biscarolasaga, I. (I975); y más recientemente Ayllón Díaz-González, J.M. (I999); Barceló Barceló, A. (2002); Morales Plaza, A. (2009a y 2009b); Bello Paredes, S.A, (2009); Ruiz de Apodaca Espinosa, A. (2010).

${ }^{4}$ A juicio de Ayllón Díaz-González, J.M. (I999, 2-5), el Derecho nuclear abarca además al Derecho constitucional, al Derecho civil, al Derecho Penal y al Derecho Internacional. Esto es predicable prácticamente de todas las disciplinas del Derecho Administrativo, como lo es el Derecho ambiental.

${ }^{5}$ Sobre las evidentes ventajas pero también los palpables inconvenientes de la participación en la toma de decisiones públicas con incidencia sobre el medio ambiente o la salud de las personas, véase Razquin Lizarraga, J.A. y Ruiz de Apodaca Espinosa, A. (2007, 283-290).

${ }^{6}$ López Cerezo, J.A. y Luján, J.L. (2000, 36 y ss.)

7 En el ámbito del Derecho Administrativo en relación con la ponderación de intereses y, porqué no decirlo, también de riesgos en las decisiones que tomas las diferentes Administraciones Públicas en estos ámbitos, merecen destacarse como guía Ortega, L. y De La Sierra, S. (2009); y antes Rodríguez de Santiago, J.M. (2000).
} 
también qué riesgos incluso ante eventos casi imposibles pero de efectos apocalípticos caso de materializarse. Tras las catástrofes de Chernobyl y Fukushima no se puede seguir afirmando la absoluta seguridad de la energía nuclear. Habría también que replantearse si la energía nuclear es rentable teniendo en cuenta los elevados costes sociales y económicos que han supuesto y supondrán a futuro los citados accidentes.

Para muchos en esta ponderación, las no demostradas ventajas de la energía nuclear son incapaces de compensar los riesgos que conllevan para la población, un riesgo que ahora sí vemos que se puede lamentablemente materializar.

Por todo ello es absolutamente necesaria, la información y la transparencia por parte de los gobiernos, de los organismos reguladores y de las propias empresas sobre las ventajas e inconvenientes de la energía nuclear ${ }^{8}$.

La decisión jurídica y político-administrativa, no puede eludir estos principios de gobernanza. Y en lo que a la protección del medio ambiente y la salud de las personas se refiere más aún, tras el Convenio de Aarhus y la posterior Ley 27/2006, de información, participación

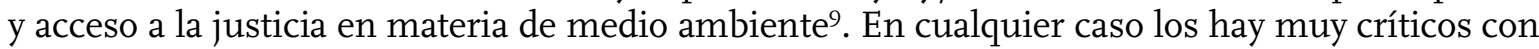
estos principios, caso de Sosa Wagner, para el que la gobernanza es una palabreja de reciente aparición más dúctil y flácida que la de gobierno, una adivinanza, que destierra la autoridad e instaura la autoridad compartida y que esconde en su seno una trampa reaccionaria (Sosa Wagner y Fuertes 20II, 33-39). Estando de acuerdo en que la participación no es codecisión, entiendo que debe ser necesaria en cualquier caso.

La participación pública en la toma de decisiones de las Administraciones públicas no tiene por finalidad garantizar la legalidad de las mismas, porque se supone que la Administración siempre actúa con respeto escrupuloso al ordenamiento jurídico. Los fenómenos de participación ciudadana tienen su justificación en aquéllos ámbitos de discrecionalidad en la actuación de la Administración, donde lo que interesa precisar es lo oportuno de la decisión frente a lo inoportuno en la preparación de las grandes decisiones administrativas que puedan tener una incidencia sobre el medio ambiente, sobre la base de las demandas sociales y su aceptación por la sociedad ${ }^{\mathrm{IO}}$.

\section{El Derecho nuclear de la Unión Europea}

La energía nuclear está directamente relacionada con el nacimiento de la actual Unión Europea. Tras el Tratado de París de I95I (CECA), los estados constituyentes vieron clara la necesidad de establecer unos mínimos regulatorios comunes relativos al uso de la energía nuclear. Como consecuencia de ello, se creo a través del Tratado de Roma de 1957, la Comunidad Europea de la Energía Atómica (CEEA), más conocida por su acrónimo inglés EURATOM. Dos de los tres tratados constitutivos de la actual Unión Europea se celebraron

\footnotetext{
${ }^{8}$ Sobre las ventajas de la energía nuclear pueden consultarse los interesantes libros de Gómez Cadenas, J.J. (2009); Lozano Leyva, M. (2009). En sentido contrario Caldicott, H. (2006) y Coderch, M. y Almirón, N. (2008).

9 Sobre esta Ley Razquin Lizarraga, J.A. y Ruiz de Apodaca Espinosa, A. (2007).

to La participación del público interesado tiene tal importancia que el Tribunal Supremo mediante sentencia de I7 de diciembre de 2008, anuló los Planes de Emergencia de las Centrales Nucleares aprobados mediante Acuerdo de Consejo de Ministros de 9 de junio de 2006, por no haber dado audiencia a la Asociación de Municipios afectados por centrales nucleares en tal procedimiento como público interesado. Igualmente debe destacarse el voto particular a la sentencia de la Audiencia Nacional de 30 de junio de 20 II en el sentido de entender necesaria la participación en la toma de decisiones que afecten la renovación de los permisos de explotación de las centrales nucleares.
} 
para resolver problemas de carácter energético. El Tratado EURATOM creó las condiciones para el desarrollo de la energía nuclear en Europa. ${ }^{\text {II }}$

El uso y la apuesta por la energía nuclear constituye en nuestros días uno de los debates en el seno de cada uno de los Estados miembros. Evidentemente, la UE nunca se ha pronunciado sobre qué fuentes de energía deben emplear los Estados miembros para garantizar el abastecimiento, cabiendo perfectamente que en unos Estados se emplee la energía nuclear y en otros no. Cada Estado es soberano en cuanto a la configuración de su propio mix de generación de energía.

La política energética comunitaria tiene una serie de objetivos concretos a los que la energía nuclear puede coadyuvar en su consecución. Estos son: sostenibilidad, competitividad y seguridad de abastecimiento, y son los mismos criterios que informan la política energética de cada uno de los Estados miembros.

El debate sobre la energía nuclear antes de Fukushima había irrumpido con fuerza en el modelo energético de la UE con base en las preocupaciones sobre la seguridad del suministro y la reducción de emisiones de gases de efecto invernadero, objetivo en torno al que giran las diferentes opciones energéticas. En primavera de 2009 la UE aprobó el llamado «Paquete Verde» en materia de energía y cambio climático. El objetivo es el de dotar a la UE de normas adecuadas para alcanzar el triple objetivo «20 para 2020 », reduciendo un $20 \%$ las emisiones de gases de efecto invernadero respecto de valores de 1990 , reducir un $20 \%$ el consumo de energía y conseguir que el $20 \%$ de la energía generada sea de fuentes renovables.

De los tres objetivos de la EURATOM, desarrollo de la energía nuclear, control de su proliferación y protección radiológica, es éste último el que más protagonismo ha ido cobrando por razones obvias: por la necesidad de seguridad frente al riesgo de las radiaciones (Sanz Larruga 2004, 53). Centrándonos en lo relativo estrictamente a la seguridad nuclear, la competencia comunitaria no ha sido ni mucho menos tan clara. La seguridad operativa de las instalaciones nucleares no constituye una competencia establecida de forma explícita por el Tratado EURATOM. Cuando se negoció el Tratado en la década de los años cincuenta, la industria nuclear era un sector incipiente y en aquel contexto lo importante era fomentar el sector nuclear, por lo que la seguridad de las instalaciones nucleares se incluyó entre las responsabilidades de los operadores nucleares, bajo el control de sus órganos nacionales. El Tratado hacía referencia a la protección radiológica, no a la seguridad de las instalaciones, si bien, como es fácilmente comprensible, ambas son inseparables.

La cuestión llegó al TJUE, que en sentencia de io de diciembre de 2002 otorgó la base jurídica suficiente para que la Comunidad pudiera regular en materia de seguridad nuclear. El TJUE establece que la Comunidad comparte competencias junto con sus Estados miembros en los ámbitos abarcados por la Convención sobre seguridad nuclear, declarando que la Comunidad es competente para establecer un sistema de autorización de instalaciones con vistas a la protección sanitaria (aunque no lo sea para autorizar la construcción o explotación de las instalaciones nucleares, algo que obviamente corresponde a cada uno de los Estados miembros). De la mano de este respaldo jurisprudencial, la Comisión reaccionó proponiendo completar el marco legal comunitario para la seguridad de las actividades nucleares ante la inminente ampliación que se avecinaba a $27 .{ }^{\mathrm{I2}}$ Por ello presentó el denominado «paquete nuclear» con dos propuestas de Directiva, una en materia de residuos y otra en materia de

\footnotetext{
${ }^{\text {II }}$ No es objeto de este breve trabajo abordar siquiera brevemente el citado Tratado constitutivo, sobre el mismo pueden verse trabajos concretos Corretjer Palomo, L (I986); Ayllón Díaz-González, J.M. (I999, 295 y ss.); más recientemente Waterloos, C. y Gallego, M. (2007) y Tromans, S.(2010, 5I-69).

${ }^{12}$ De hecho la quinta ampliación de la Comunidad ha resaltado los temas relacionados con la seguridad nuclear. La Agenda 2000 determinó en un principio, tras el análisis realizado por los órganos reguladores, los reactores que en un futuro próximo debían ser desmantelados por no poderse mejorar con un coste económico razonable.
} 
seguridad de las instalaciones nucleares. La justificación era obvia: era el momento de que la Comunidad afirmase claramente sus competencias en cuanto a la seguridad de las instalaciones nucleares y de adoptar una normativa vinculante para los 27 desde un punto de vista jurídico.

La existencia de una minoría de bloqueo en lo referente a los fondos destinados a la financiación hizo imposible la adopción de las citadas Directivas, a pesar de las modificaciones introducidas a la propuesta inicial con el fin de desbloquear su aprobación. Las propuestas presentadas por la Comisión Europea iban en el sentido de unificar normas de seguridad e imponer plazos para construir depósitos de seguridad de los residuos nucleares generados por las centrales.

\section{III.I. La Directiva de seguridad nuclear}

La primera de las Directivas aprobadas del citado «paquete nuclear» que vio la luz es la Directiva 2009/7I/Euratom, del Consejo de 25 de junio, por la que se establece un marco comunitario para la seguridad nuclear de las instalaciones nucleares ${ }^{13}$. Esta Directiva tiene como objetivo establecer un marco comunitario para mantener y promover la mejora continua de la seguridad nuclear y su regulación, garantizando que los Estados miembros adopten disposiciones nacionales adecuadas para un alto nivel de seguridad nuclear. Estamos ante una Directiva de mínimos exigibles en cada uno de los Estados miembros con centrales nucleares. Las obligaciones que se establecen para los Estados son las de establecer un marco legislativo, reglamentario y organizativo de seguridad, autorización y supervisión de instalaciones nucleares. Para ello, se exige la existencia de una autoridad reguladora competente que además ha de ser independiente. Por último, se contienen obligaciones relativas a los titulares de instalaciones, su responsabilidad, su compromiso de mejora continua y, por supuesto, la necesaria información al público. El plazo de transposición de esta Directiva concluía este año, el 22 de julio de 20II. Si bien, como veremos, nuestra legislación estatal en materia nuclear ya cumple con creces las obligaciones previstas en esta Directiva, tendrá que llevar a cabo una transposición formal de la misma. Las obligaciones que la Directiva establece derivan de una lógica aplastante que ya venía siendo observada por todos los Estados miembros con instalaciones nucleares en funcionamiento, por lo que, a mi juicio, la transposición de la Directiva por cada uno de los Estados no deberá plantear mayores problemas.

\section{III.2. La Directiva de residuos radiactivos y gestión del combustible gastado}

La segunda de las Directivas del frustrado paquete nuclear, relativa a los residuos y al combustible gastado, ya es ahora una realidad en la Directiva 20II/70/Euratom, de I9 de julio. La regulación relativa a los residuos radiactivos afecta a todos los Estados miembros con independencia de que en su territorio haya o no centrales nucleares, ya que todos generan residuos radiactivos procedentes de la investigación o de la medicina nuclear. Anualmente se producen en la UE unos 7.000 metros cúbicos de residuos de alta actividad, almacenándose en depósitos provisionales que no constituyen una solución a largo plazo y que exigen una supervisión y mantenimiento permanentes.

De acuerdo con esta Directiva, cada Estado debe asumir la obligación ética de evitar a las generaciones futuras cualquier carga indebida en relación con el combustible nuclear gastado y los residuos radiactivos, así como los residuos radiactivos que se derivarán previsiblemente del desmantelamiento de las instalaciones nucleares existentes. La Directiva refuerza el principio de responsabilidad nacional $y$, evidentemente, el principio de

\footnotetext{
${ }^{13}$ Sobre esta Directiva, entre otros, Tromans, S. (2010, 72-74); Garriba, M., Chirtes, A. y Nauduzaite, M. (2009, 24-32); Pouleur, Y. y Krs, P. (2010, 5-31).
} 
responsabilidad primordial del titular de la licencia por la seguridad de la gestión del combustible nuclear gastado, bajo la supervisión de la autoridad reguladora competente.

En particular, la Directiva obliga a los Estados a elaborar programas nacionales en el plazo de 4 años tras la adopción de la Directiva que deberán incluir planes para la construcción y gestión de las instalaciones de almacenamiento, fijando un calendario de construcción concreto. Se trata de que todos los Estados adopten medidas positivas en este ámbito, evitándose la táctica conocida de «esperar y ver». Tales planes nacionales deberán ser notificados a la Comisión que podrá solicitar su modificación. Estos planes deben contener un inventario de residuos (presente y futuro), planes de almacenamiento, plazos de ejecución, coste económico y planes de financiación. El contenido de tales planes se detalla en su artículo I2: deben contener objetivos, etapas, calendario, inventario, soluciones técnicas, responsabilidades de aplicación, transparencia, costes y financiación.

Al igual que en la Directiva de seguridad, se requiere la existencia de una autoridad reguladora competente independiente, con facultades jurídicas y financieras necesarias para controlar y garantizar la seguridad de la gestión por parte del titular o titulares de la autorización. En España este organismo es evidentemente el CSN.

Los titulares de la gestión deberán poseer una licencia que determinará su responsabilidad y la exigencia de ser evaluados regularmente por la autoridad reguladora con el fin de comprobar y mejorar continuamente la seguridad de la instalación. En España el titular de las licencias es ENRESA, titular del servicio público esencial de gestión de los residuos radiactivos y nucleares.

De acuerdo con la Directiva los residuos radiactivos serán almacenados definitivamente en el Estado miembro en el que se hayan generado si bien admite la posibilidad de que dos o más Estados miembros puedan concertarse para utilizar un depósito definitivo ubicado en uno de ellos o bien que sea un tercer país, con lo que finalmente se admite la exportación de residuos radiactivos con arreglo a una serie de cautelas ${ }^{14}$. En esto cambia la propuesta inicial de Directiva que en principio prohibía expresamente la exportación de residuos nucleares a países de fuera de la UE para su almacenamiento definitivo.

La información y la transparencia al público en general adquieren también gran protagonismo en esta Directiva. Para conseguirla, se señala que debe garantizarse una información pública efectiva y debe brindarse a todas las partes implicadas, incluidas las autoridades locales y la población, la oportunidad de participar en todos los procesos de toma de decisiones, de conformidad con las obligaciones asumidas a escala nacional e internacional. El público deberá ser informado y deberá tener la posibilidad de participar en la toma de decisiones sobre la gestión de los residuos nucleares en cada Estado.

La Directiva deberá ser transpuesta antes del 23 de agosto de 2013 y los Estados miembros deberán remitir antes del 23 de agosto de 2015 el contenido de su Programa nacional con el contenido que la Directiva especifica. Además antes del 25 de agosto de 2015 deberán presentar un informe sobre la aplicación de la citada Directiva.

Necesariamente, lo que se establezca en los Planes nacionales deberá ser cumplido en los plazos previstos y la Comisión vigilará su cumplimiento.

${ }^{14}$ Se detallan en el artículo 4.4 de la Directiva, estos son que el «tercer país» haya celebrado un acuerdo con la Comunidad que cubra tal gestión de combustible gastado o sea parte de la Convención conjunta, que disponga de programas de gestión y almacenamiento con elevado nivel de seguridad y que la instalación de almacenamiento definitivo esté autorizada. 


\section{El Derecho Nuclear en España}

Es cuanto menos curioso el salto convulsivo que la normativa en materia de instalaciones nucleares ha experimentado en nuestro ordenamiento jurídico en 20II tras muchos años. Como es sabido la regulación de instalaciones nucleares deriva de una Ley preconstitucional de 1964 y de un reglamento de instalaciones nucleares de i973 que fue sustituido por otro de I999. Junto a esto es necesario destacar la profusa normación de carácter reglamentario que ha ido generando el CSN a través de las denominadas instrucciones normativas.

En este último año 20II y dentro de la ahora extinta legislatura se han aprobado varias leyes y normas reglamentarias que han afectado y de qué manera el régimen jurídico de las instalaciones nucleares. Todo ello, jalonado con el incidente de la central nuclear de Fukushima de fondo, con la reciente sentencia de la Audiencia Nacional de 30 de junio de 20 II en relación con la reducida renovación temporal del permiso de explotación de la central nuclear de Santa María de Garoña y, por último con, la cuestión del Almacén Temporal Centralizado (ATC), aún pendiente para albergar el combustible gastado de nuestras centrales nucleares.

Desde la Ley de economía sostenible, pasando por la Ley de responsabilidad por daños nucleares, el panorama normativo nuclear ha experimentado una importante transformación.

\section{IV.I. La Ley de Energía Nuclear de I964 y el Reglamento de Instalaciones Nucleares y Radiactivas de 1999}

La regulación de la energía nuclear en España está dispersa en varias normas legales y reglamentarias. Como es bien sabido, el marco legal de la generación de energía nuclear en España tiene como norma cabecera una ley preconstitucional que ha sido objeto de sucesivas reformas pero que sigue vigente en nuestros días. Se trata de la Ley 25/1964, de 29 de abril, sobre Energía nuclear (LEN) que recoge los principios fundamentales sobre el desarrollo de la energía nuclear y sobre la protección frente al riesgo de radiaciones ionizantes.

Además de la LEN, también se encuentra la regulación nuclear en diferentes disposiciones adicionales de la Ley 54/1997 del Sector Eléctrico, en la Ley I5/1980, de 22 de abril, del Consejo de Seguridad Nuclear (LCSN) y en numerosas normas reglamentarias, incluidas las instrucciones del CSN. Incluso el difunto RAMINP hacía referencia a las instalaciones nucleares y a la necesidad de licencia de actividad clasificada

La LEN consta de I3 capítulos dedicados a regular, entre otros, la investigación y la enseñanza nuclear; la prospección, investigación, explotación y comercialización de los minerales radiactivos y sus concentrados; el régimen de autorizaciones; las medidas de seguridad y protección contra las radiaciones ionizantes, y las infracciones y sanciones administrativas. El régimen de responsabilidad civil derivada de daños nucleares y la cobertura del riesgo nuclear que venía regulándose en la LEN ha sido objeto ahora de una ley específica, la reciente Ley I2/20II, a la que haremos referencia más adelante.

Los objetivos de esta norma básica son los de fomentar el desarrollo de las aplicaciones pacíficas de la energía nuclear en España y regular su puesta en práctica en todo el territorio nacional, así como la protección de vidas, salud y haciendas contra los peligros derivados de la energía nuclear. Para ello, la LEN establece el requisito obligatorio de control previo y autorización de cualquier instalación o actividad relacionada con la energía nuclear y con carácter básico establece el sistema de inspección, control y sanción en materia nuclear. 
IV.2. Las autorizaciones relativas a las instalaciones nucleares y su naturaleza jurídica

Obviamente, la autorización es la técnica de intervención y control previo a la instalación de centrales nucleares y está sujeta a posterior renovación. Técnica a través de la que se plasma el principio de prevención tan fundamental en materia de Derecho Ambiental.

La LEN no dedicaba más que un simple artículo a la autorización de instalaciones nucleares, en concreto el artículo 28 , cuya brevísima redacción inicial ha sido ahora extendida sustancialmente por la modificación que sobre la LEN ha operado la reciente Ley I2/20II, de responsabilidad por daños nucleares. El nuevo artículo 28 LEN (redactado según la Disposición Adicional Tercera de la Ley I2/20II) es más extenso habiéndose añadido tres nuevos apartados referidos a la titularidad de las instalaciones por una sola persona jurídica. Así se señala que:

I. Las instalaciones nucleares y radiactivas estarán sometidas a un régimen de autorizaciones emitidas por el Ministerio de Industria, Turismo y Comercio, previo informe preceptivo del Consejo de Seguridad Nuclear, oídas en materia de ordenación del territorio y medio ambiente las Comunidades Autónomas en cuyo territorio se ubique la instalación o la zona de planificación prevista en la normativa básica sobre planificación de emergencias nucleares y radiológicas.

El régimen jurídico de las autorizaciones se establecerá reglamentariamente y definirá las autorizaciones aplicables a cada una de las fases de vida de dichas instalaciones, que se referirán al menos a la selección de emplazamientos, a la construcción, a la puesta en marcha y el funcionamiento, y a su desmantelamiento y clausura, según corresponda.

El desarrollo reglamentario al que hace referencia el 28.I in fine se cubre en la actualidad por el Real Decreto 1836/1999, de 3 de diciembre, de instalaciones nucleares y radiactivas, siendo el Ministerio de Industria, Turismo y Comercio el órgano competente para otorgar todas las autorizaciones necesarias para las centrales nucleares.

En desarrollo de la LEN se han aprobado varios reglamentos. En lo que concierne a las instalaciones nucleares nos interesa el Real Decreto I836/1999, de 3 de diciembre por el que se aprueba el Reglamento sobre instalaciones nucleares y radiactivas (RINR en lo sucesivo), que desarrolla con detalle el régimen de autorizaciones previsto en la LEN. Este Real Decreto desarrolla los principios contenidos en la LEN regulando el régimen de autorizaciones administrativas, pruebas, puesta en marcha y operación de las centrales nucleares. También desarrolla el régimen de las licencias del personal que opere en dichas instalaciones, las obligaciones de los titulares de instalaciones y el régimen de las actividades de inspección y control.

Las instalaciones nucleares se clasifican en cuatro categorías: centrales nucleares, reactores nucleares, fábricas que utilicen combustible nuclear para producir sustancias nucleares o traten sustancias nucleares y, por último, las instalaciones de almacenamiento de sustancias nucleares.

Para las citadas instalaciones, se dispone la tradicional técnica preventiva de autorización. La autorización corresponde al Ministerio de Industria y Energía previo informe favorable del organismo regulador e independiente, el Consejo de Seguridad Nuclear.

La LEN y el RINR regulan una serie de autorizaciones para la instalación y funcionamiento de este tipo de instalaciones. No es objeto de este capítulo entrar en su estudio, pero sí me parece importante destacar que cualquier instalación nuclear existente debe contar con las siguientes autorizaciones:

- Autorización previa de emplazamiento, consistente en un reconocimiento oficial del objetivo propuesto por el solicitante y de la idoneidad del emplazamiento elegido. Esta autorización es claramente discrecional. 
- Autorización de construcción, siguiente a la anterior que faculta para iniciar la construcción de la instalación.

- Autorización de explotación; faculta para cargar el combustible nuclear o introducir sustancias nucleares en la instalación una vez construida, a realizar el programa de pruebas y a operar la instalación de acuerdo con las condiciones establecidas. Se concede con carácter provisional hasta la finalización satisfactoria de las pruebas nucleares, para pasar a ser definitiva. Esta autorización cuando es inicial es reglada. En cuanto a las renovaciones, se duda sobre su naturaleza reglada o discrecional.

- Autorizaciones de modificación; ejecución y montaje de la modificación; desmantelamiento; almacenamiento temporal de sustancias nucleares y cambio de titularidad.

Cabe destacar que ni la LEN ni el reglamento establecen plazo alguno de vigencia de las autorizaciones. En el caso de la autorización de explotación, si bien se ha venido renovando por un plazo de diez años, previo informe preceptivo y vinculante en sentido obstativo del Consejo de Seguridad Nuclear. En nuestros días, como es sabido, la Orden Ministerial ITC/I785/2009, de 3 de julio, por la que se acuerda como fecha de cese definitivo de la explotación de la Central nuclear de Santa María de Garoña el día 6 de julio de 20I3, y se autoriza su explotación hasta dicha fecha, supuso una renovación por cuatro años de la citada central pese al informe favorable del CSN de prorrogarla por diez años. Tampoco es claro si su concesión debiera ser reglada al cumplir la central con los requisitos técnicos de acuerdo con el informe del CSN, o si bien es discrecional, pudiendo el Gobierno de manera motivada rebajar ese plazo. La cuestión ha sido resuelta por la sentencia de 30 de junio de $201 \mathrm{I}$, de la sala de lo contencioso de la Audiencia Nacional. Lo cierto es que argumentos sólidos los hay en ambos sentidos. A favor de la discrecionalidad de la autorización a otorgar por parte del Ministerio puede señalarse que no hay norma alguna anterior al actual artículo 98.3 LES 2/20II que establezca qué criterios debe seguir la Administración, y que, si el legislador hubiese querido que la autorización fuese reglada, hubiera establecido carácter vinculante in totum al dictamen del CSN. A favor del carácter reglado pueden argumentarse las previsiones de los artículos 7 y 5 del RINR de I999. En estos artículos se establece que en la renovación del permiso de explotación se establecerán las condiciones de la renovación próxima (artículo 7) y, por otro lado, el artículo 5 remite en cuanto al procedimiento al de concesión inicial. Y en el otorgamiento inicial sí que puede afirmarse que estamos ante una autorización reglada una vez obtenida la autorización de emplazamiento, de construcción y el informe favorable del CSN para la explotación.

La Audiencia Nacional, en su sentencia de 30 de junio de 20II, no deja lugar a dudas sobre el carácter discrecional de la prórroga del permiso de explotación de la central nuclear, si bien afirma que en ella concurren numerosos elementos reglados. Así, sobre la discrecionalidad o no de las renovaciones de autorización de explotación de centrales nucleares, señala en su FJ I7 ${ }^{\circ}$

«(...)el que los repetidos elementos reglados operen como contenido mínimo e ineludible de la renovación de la autorización de explotación de la central nuclear, no significa que sean los únicos que puedan tenerse en cuenta en la concesión y/o renovación de tal autorización, pues junto a ese mínimo imprescindible, y que se concreta esencialmente en la garantía de seguridad concurren, en la decisión adoptada en el presente caso, otra serie de circunstancias, ajenas a las materias de seguridad nuclear y emisiones radiológicas, que han de ser valoradas a efectos de pronunciarnos sobre la adecuación o no a Derecho de la Orden Ministerial recurrida. Se trata, por tanto, de resolver si dadas las especialidades existentes en la materia y por los motivos que a continuación se exponen, pueden operar otros motivos que exceden de dicho ámbito reglado.»

«Por otra parte, y tal y como pone de manifiesto la Abogada del Estado en la contestación, son evidentes las especificidades que concurren en la generación de energía nuclear, que demandan ciertas especialidades normativas y que giran en torno a dos pilares sobre los que se construye la misma: a) la seguridad nuclear y protección radiológica de un lado y b) la gestión de residuos radiactivos. Ha de tenerse en cuenta que en la valoración del coste total de la gestión futura de dichos residuos existe un alto grado de incertidumbre, pues aunque hoy existen soluciones de gestión de 
carácter temporal (ATC y ATI), la gestión definitiva de combustible nuclear gastado y de residuos de alta actividad no cuenta con soluciones probadas, por lo que el coste total de actividad industrial de generación de energía eléctrica mediante energía nuclear mantiene un incuestionable grado de incertidumbre, máxime a tenor de la permanencia de características de radiotoxicidad en muchos de los residuos durante un periodo de tiempo de miles de años.»

Para continuar afirmando, en su FJ I $8^{\circ}$ :

«Pero además, y sobre todo, existe una última y poderosa justificación que legitima el pronunciamiento no reglado de la Orden Ministerial recurrida, y que consiste en que la misma ha sido dictada en un ámbito, el de la energía nuclear, que no solo es muy específico, como se ha indicado, sino también controvertido, generador de un gran debate popular, debido sobre todo a los riesgos inherentes a tal clase de energía (emisiones radiológicas, residuos radioactivos...), ámbito en el que sin duda, y dada dicha especificidad y controversia, puede intervenir una determinada dirección u orientación de la política del Gobierno, en cuanto órgano constitucional supremo».

\section{IV.3. El Consejo de Seguridad Nuclear como administración independiente ${ }^{15}$}

IV.3.I. Regulación y naturaleza

La Ley 15/I980, de 22 de abril, de creación del Consejo de Seguridad Nuclear, es una ley que tiene tanta importancia como la propia LEN porque desarrolla las funciones y cometidos del CSN, el organismo competente en materia de seguridad nuclear y protección radiológica.

Como es sabido, el CSN es una de las denominadas Administraciones independientes con el fin de eludir el control y dirección del Gobierno y llevar a cabo sus funciones con total independencia, dando cuenta de las mismas exclusivamente a las Cortes Generales. El CSN se constituye como un Ente de Derecho Público, independiente de la Administración General del Estado, con personalidad jurídica y patrimonio propio e independiente de los del Estado. Se rige por un Estatuto propio.

La mayor independencia del CSN se refleja en sus relaciones con el Gobierno y su Administración. Así, el nombramiento y cese de sus miembros (art. 7 LCSN) se configura como una especie de procedimiento de codecisión Gobierno-Parlamento. El Gobierno ni ninguno de sus miembros está facultado para asistir a sus deliberaciones y tampoco está sujeto a control alguno de eficacia. Por otro lado, el CSN elabora su propio Estatuto, de modo que al Gobierno sólo le corresponde aprobarlo mediante Real Decreto, no existiendo previsión alguna de que sus resoluciones o instrucciones sean recurribles en alzada ante el Ministerio de Industria o el Gobierno. No obstante, en el plan estratégico 20II-I6 el CSN proclama de manera expresa su neutralidad sobre la energía nuclear, pide más independencia respecto del Gobierno con la idea de depender exclusivamente del Parlamento. El mismo plan establece de nuevo la transparencia como uno de sus pilares.

Sus funciones más importantes son las de asesorar y proponer al Gobierno las reglamentaciones necesarias en materia de seguridad nuclear; elaborar y aprobar instrucciones, circulares y guías de carácter técnico pero de un indudable valor normativo; emitir informes previos que tienen carácter preceptivo y vinculante en sentido obstativo a la concesión de autorizaciones; realizar toda clase de inspecciones en instalaciones nucleares; proponer la apertura de expedientes sancionadores; coordinar las medidas de apoyo en situaciones de emergencia.

Is Sobre la naturaleza y funciones del Consejo de Seguridad Nuclear, véase por todos López Ramón, F. (I99I); Betancor Rodríguez, A. (I994, 97-II3); Morales Plaza, A. (2003 y 2009b, 466-5I4); Parejo Alfonso, L. (2009). 
El Real Decreto I440/20IO, de 5 de noviembre, aprobó el nuevo Estatuto del Consejo de Seguridad Nuclear, derogando el anterior Real Decreto de 30 de abril de iو82, que regulaba el Estatuto del CSN. La reforma se justifica en las múltiples reformas producidas en el marco normativo que afecta al Consejo, entre otras las recientes derivadas de la Ley 33/2007, que ha significado una amplia transformación en el régimen jurídico del Consejo, fortaleciendo y garantizando la independencia del organismo y desarrollando los mecanismos necesarios para promover y potenciar la transparencia, la participación y el acceso de los ciudadanos a la información relevante en materia de Seguridad Nuclear y Protección Radiológica.

A lo largo de sus cinco títulos, el nuevo Estatuto del Consejo establece las competencias del organismo regulador, la estructura organizativa, el régimen de personal, la contratación y asistencia jurídica así como el régimen patrimonial, presupuestario y de control de la gestión económico-financiera y contable.

\section{IV.3.2. La necesaria transparencia en su actividad}

La necesaria transparencia del CSN, introducida por la Ley 33/2007, en el reciente Estatuto se confirma en su artículo I5, que establece que el CSN respetará en su actuación el principio de transparencia e informará a los ciudadanos sobre todos los hechos relevantes relacionados con el funcionamiento de las instalaciones nucleares y radiactivas, dentro o fuera de las mismas, especialmente en todo aquello que hace referencia a su funcionamiento seguro, al impacto radiológico para las personas y el medio ambiente, a los sucesos e incidentes ocurridos en las mismas, así como a las medidas correctoras adoptadas para evitar su reiteración. La información se hará pública por el CSN mediante cualesquiera medios informáticos y telemáticos que aseguren su máxima difusión.

Asimismo, el Consejo de Seguridad Nuclear, da publicidad a los acuerdos por él adoptados, con exposición clara de los asuntos tratados, de los motivos del acuerdo y del resultado de la votación, a través de medios informáticos y telemáticos que aseguren la máxima difusión. Por la misma vía, se da publicidad, entre otros actos, a las Instrucciones y Guías de Seguridad aprobadas por el Consejo, las actas de las sesiones del Pleno y del Comité Asesor, las actas de inspección, los Convenios de Encomienda formalizados con las Comunidades Autónomas y el Informe anual al Parlamento.

Una de las herramientas recogidas en el nuevo marco legal, es la figura del Comité Asesor, cuya misión es emitir recomendaciones y propuestas al CSN para mejorar la transparencia, el acceso a la información y la participación pública en las materias de su competencia.

Tal es la obsesión del CSN de cumplir con su compromiso de información y transparencia que el pasado 8 de marzo de $201 \mathrm{I}$, activaba una cuenta en Twiter ${ }^{16}$, red social conocida, con el objeto de acercar al público en general, contenidos relacionados con su función, tales como novedades reguladoras o avances en seguridad nuclear.

Con estas modificaciones lejos quedan supuestos como el que dio lugar a la sentencia de la Audiencia Nacional de 29 de febrero de 2000 en relación con la denegación por parte del CSN del acceso a las actas de inspección relacionadas con un supuesto escape radiactivo en la factoría que Acerinox posee en Los Barrios (Cádiz), solicitada por la Asociación Ecologista AEDENAT. ${ }^{\text {r7 }}$ La Audiencia Nacional estimo el recurso considerando que el CSN no tenía porqué denegar tal acceso con base en la entonces vigente Ley 38/1995 de acceso a la información ambiental. Esta sentencia fue confirmada por el Tribunal Supremo en sentencia

\footnotetext{
${ }^{16} @$ CSN_es

${ }^{\text {I7 }}$ Sobre esta sentencia, puede verse el acertado comentario a la misma de Entrena Ruiz, D. (200I).
} 
de 17 de febrero de 2004, desestimando el recurso de casación interpuesto por la Abogacía del Estado. En este caso, aparte de la importancia que tiene el aspecto nuclear, la actitud que tuvo el CSN fue especialmente grave al tratarse de una Administración independiente cuya existencia se justifica por la necesidad de regular un ámbito material determinado de forma ajena a las vicisitudes políticas y gestionado por expertos técnicos.

\section{IV.3.3. La potestad normativa del CSN}

La LCSN otorga al CSN la facultad de «aprobar las instrucciones, circulares y guías de carácter técnico relativas a las instalaciones nucleares y radiactivas y las actividades relacionadas con la seguridad nuclear».

La potestad para dictar instrucciones propias por parte del CSN se introdujo mediante la Ley I4/I999, de 4 de mayo, de tasas y precios públicos por servicios prestados por el CSN. Desde entonces, el CSN lleva a cabo toda una labor normativa, reglamentaria, de regulación del sector en materia de seguridad y buenas prácticas. Una potestad reglamentaria atribuida ex lege, no configurada como una especie de producto normativo subordinado a otras disposiciones previas dictadas por el Gobierno o un Ministerio. Estas instrucciones tienen carácter normativo. De acuerdo con el artículo 2 LCSN, el CSN tiene la facultad de elaborar y aprobar las instrucciones, circulares y guías de carácter técnico relativos a las instalaciones nucleares y radiactivas y las actividades relacionadas con la seguridad nuclear. Entre las instrucciones del CSN se pueden distinguir aquellas que tienen un carácter general e indeterminado de las que tienen como destinatario concreto una instalación o actividad autorizada. Esta competencia normativa es habitual en los organismos conocidos como «administraciones independientes», caso del CSN.

Las instrucciones constituyen un auténtico poder normativo del CSN autónomo en su ámbito de actuación, seguridad nuclear principalmente, y evidentemente subordinadas a las normas de rango superior que configuran el ordenamiento jurídico nuclear español. Estas instrucciones son normas reglamentarias que tienen un carácter abstracto y general, tanto en sentido subjetivo como objetivo. Son normas técnicas que, en materia de seguridad nuclear y protección radiológica, tienen carácter vinculante para los sujetos afectados por su ámbito de aplicación, constituyendo su inobservancia la correspondiente infracción administrativa. Estas instrucciones normativas se aprueban con arreglo al correspondiente procedimiento reglamentario (propuesta, informe, aprobación) y son publicadas en el Boletín Oficial del Estado. Las instrucciones del CSN son comunicadas al Congreso de los Diputados y las que afectan a la protección radiológica también a la UE en aplicación del artículo 33 TCEEA.

Son numerosas las Instrucciones aprobadas por el CSN en ejercicio de este poder reglamentario autónomo del que es titular ${ }^{18}$. En las mismas puede verse que además de ser

\footnotetext{
${ }^{18}$ Podemos citar las siguientes Instrucciones del CSN que, por supuesto, tienen carácter reglamentario y obligatorio:

- Instrucción IS-oI, reguladora del carné radiológico.

- Instrucción IS-02, sobre actividades de recarga en centrales nucleares.

- Instrucción IS-03, sobre expertos en protección contra las radiaciones ionizantes.

- Instrucción IS-04, sobre documentación de centrales nucleares en desmantelamiento.

- Instrucción IS-05, sobre valores de exención para nucleidos.

- Instrucción IS-o6, sobre programas para la formación de trabajadores externos.

- Instrucción IS-07, sobre campos de aplicación de licencias de personal de instalaciones radiactivas.

- Instrucción IS-o8, sobre criterios aplicados por el CSN para exigir asesoramiento en protección radiológica.
} 
posteriores a I999, éstas se refieren exclusivamente a aspectos de funcionamiento de las instalaciones, con olvido de otras fases previas y posteriores como pueden ser las relativas al emplazamiento o al desmantelamiento.

Uno de los aspectos novedosos introducidos por la última reforma de la LCSN a través de la Ley 33/2007, es el relativo a la participación pública en la elaboración de tales disposiciones, como consecuencia de la Ley 27/2006, de información participación y acceso a la justicia en materia ambiental. El Derecho ambiental ha condicionado el Derecho nuclear.

\section{La reciente reforma del Ordenamiento Nuclear en España}

El proceso de renovación de las autorizaciones de explotación de las centrales nucleares en España, el compromiso político del Gobierno en relación con la energía nuclear y la permanente búsqueda de garantías económicas, de suministro y de seguridad han puesto sobre la mesa en los últimos tres años varias propuestas y, ahora, realidades de modificación normativa en materia nuclear. En unos casos como consecuencia de la inmediata transposición

- Instrucción IS-o9, sobre criterios de protección física.

- Instrucción IS-Io, sobre criterios de notificación de sucesos en centrales nucleares.

- Instrucción IS-II, sobre licencias de personal de operación de centrales nucleares.

- Instrucción IS-I2, sobre requisitos de cualificación y formación del personal sin licencia en el ámbito de las centrales nucleares.

- Instrucción IS-I3, sobre criterios radiológicos para la liberación de emplazamientos de instalaciones nucleares.

- Instrucción IS-I4, sobre la Inspección Residente del CSN en centrales nucleares.

- Instrucción IS-I5, sobre vigilancia de la eficacia del mantenimiento en centrales nucleares.

- Instrucción IS-I6, sobre períodos de archivo de documentos y registros de las instalaciones radiactivas.

- Instrucción IS-I7, sobre homologación de cursos de formación y acreditaciones del personal que dirija u opere equipos de rayos $\mathrm{X}$ de diagnóstico médico.

- Instrucción IS-I8, sobre los criterios para la notificación de sucesos e incidentes radiológicos en instalaciones radiactivas.

- Instrucción IS-I9, sobre los requisitos del sistema de gestión de las instalaciones nucleares.

- Instrucción IS-20, sobre requisitos de seguridad relativos a contenedores de almacenamiento de combustible gastado.

- Instrucción IS-2I, sobre requisitos aplicables a las modificaciones en las centrales nucleares.

- Instrucción IS-22, sobre requisitos de seguridad para la gestión del envejecimiento y la operación a largo plazo de centrales nucleares.

- Instrucción IS-23, sobre inspección en servicio en centrales nucleares.

- Instrucción IS-24, por la que se regulan el archivo y los periodos de retención de documentos y registros de las instalaciones nucleares.

- Instrucción IS-25, sobre criterios y requisitos sobre la realización de los análisis probabilistas de seguridad y sus aplicaciones a las centrales nucleares.

- Instrucción IS-26, sobre requisitos básicos de seguridad nuclear aplicables a las instalaciones nucleares.

- Instrucción IS-27, sobre criterios generales de diseño de centrales nucleares.

- Instrucción IS-29, sobre seguridad en un almacén temporal centralizado del combustible gastado.

- Instrucción IS-30, sobre requisitos del programa de protección contra incendios en centrales nucleares.

- Instrucción IS-3I, sobre control radiológico de los materiales residuales generados en las instalaciones nucleares. 
de las Directivas citadas; en otros casos como consecuencia de exigencias de transparencia en información.

V.I. La ley 2/20II, de 4 de marzo, de economía sostenible

La reciente Ley $2 / 20$ II, de economía sostenible, criticada por parte de la doctrina ${ }^{\mathrm{Ig}}$, hace un par de menciones a la legislación nuclear vigente.

La primera de ellas, relacionada con la decisión política de riesgo, dentro de su artículo $79.3 \mathrm{C})^{2 \circ}$ en relación con los objetivos de la planificación energética indicativa para el año 2020: «Determinar los niveles de participación de la energía nuclear en la cesta de generación energética, de acuerdo con el calendario de operación de las centrales existentes y con las renovaciones que, solicitadas por los titulares de las centrales, en el marco de la legislación vigente, en su caso correspondan, teniendo en cuenta las decisiones del Consejo de Seguridad Nuclear sobre los requisitos de seguridad nuclear y protección radiológica, la evolución de la demanda, el desarrollo de nuevas tecnologías, la seguridad del suministro eléctrico, los costes de generación eléctrica y las emisiones de gases de efecto invernadero, y ateniéndose en todo caso al marco de referencia establecido por la normativa europea vigente.»

Esto no impediría que la CN de Garoña pudiera seguir funcionando a partir de 20I3, más teniendo en cuenta que desde la Subcomisión de Energía del Congreso parece ser válida la opción nuclear en el horizonte de 2035 dentro del análisis de la estrategia energética que en España se ha estado llevando a cabo ${ }^{21}$. Si bien, como hemos visto, de momento la sentencia de la Audiencia Nacional de 30 de junio de $201 \mathrm{~s}$ ha ratificado la legalidad de la Orden ministerial de julio de 2009 .

V.2. La Ley I2/20II, sobre responsabilidad civil por daños nucleares o producidos por materiales radiactivos

El riesgo que más alarma y más disuade a la opinión pública y a la sociedad en general respecto a la apuesta por la energía nuclear es el riesgo de un accidente. El Derecho Nuclear es un compendio de normas de seguridad, de conjura de los riesgos, pero también de responsabilidad caso de que tales riesgos se materializasen en un catastrófico siniestro.

\footnotetext{
I9 Sobre la denominada «Better Regulation», de inexcusable y recomendable lectura Betancor Rodríguez, A. (2009).

${ }^{20} \mathrm{El}$ iter legislativo de este precepto ha sido muy debatido y objeto de varias modificaciones. En el proyecto de ley inicial se preveía «Mantener de conformidad con la normativa vigente, el calendario de cumplimiento de los 40 años de vida útil de las centrales del parque nuclear existente, de acuerdo con su vida de diseño, incorporando en todo caso a dicha normativa el cumplimiento de requerimientos medioambientales $y$ de seguridad específicos en los casos de renovación extraordinaria de las concesiones por encima de dicho plazo, derivadas del desarrollo de nuevas tecnologías de su necesidad de garantizar el suministro». Con ello cabía perfectamente la posibilidad incluso de continuar operando cuando se superen los 40 años de vida útil de las centrales nucleares. En el último plazo de enmiendas, el Grupo Socialista en el Congreso modificó esta previsión por «Mantener el calendario de operación de las centrales del parque nuclear existente, considerando el plazo de 40 años para el que fueron diseñadas y teniendo en cuenta el desarrollo de nuevas tecnologías, la seguridad del suministro eléctrico, los costes de generación eléctrica y las emisiones de gases de efecto invernadero». Como se ve, se retiraba en este punto la mención a la ampliación extraordinaria del permiso de explotación a centrales nucleares que superen los 40 años de vida para el que fueron diseñadas.

${ }^{2 \pi}$ En cualquier caso, siguiendo con el «efecto Fukushima», el 29 de marzo de 20 II, el grupo socialista registraba en el Congreso una iniciativa para mantener el cierre de Garoña en 20I3, como decidió el Gobierno. Con la iniciativa, los socialistas consiguen que el PP vote su apoyo a la prórroga de la nuclear hasta 2019 e implican al Congreso en el cierre, cuando aún estaba pendiente de un recurso en la Audiencia Nacional ahora resuelto por la citada sentencia de la Audiencia Nacional de 30 de junio de 20 II.
} 
Inicialmente esta regulación se encontraba en la LEN en un capítulo referido a la responsabilidad civil de las instalaciones nucleares. La Ley I2/20II regula la responsabilidad civil nuclear de conformidad con los Convenios internacionales de París y Bruselas, lo que se complementa con los Protocolos de los Convenios de París y de Bruselas ratificados por España con fecha I8 de noviembre de 2005 .

Esta ley introduce las siguientes novedades: los titulares de instalaciones nucleares están obligados a establecer una cobertura de responsabilidad civil por daños nucleares de I200 millones de euros. La iniciativa eleva a I200 millones de euros la responsabilidad por accidentes nucleares para las empresas titulares de las instalaciones. La ley establece que por encima del tramo de responsabilidad mínima obligatoria del explotador que fija el Convenio de París, el segundo tramo de compensación complementaria que establece el Convenio de Bruselas entre 700 millones de euros y I200 millones de euros también tiene que ser garantizado íntegramente por los explotadores de las instalaciones. A tal efecto, éstos están obligados a establecer una cobertura de responsabilidad civil por daños nucleares, en las condiciones que se establecen en esta ley, por una cuantía de i200 millones de euros mediante alguno de los procedimientos autorizados que se contemplan en el capítulo II del título I de la ley.

Los Convenios de París y Bruselas estipulan una responsabilidad mínima de 700 millones y permiten a los Estados ampliarla hasta los I200 millones opción elegida por España al considerar que deben ser los titulares de las instalaciones quienes asuman las responsabilidades ante eventuales daños. Evidentemente, para las instalaciones de riesgo reducido y de transporte, esa cantidad puede ser rebajada por el Ministerio hasta los 70-80 millones de euros.

Dentro del concepto de daño nuclear que debe ser cubierto se incluyen también los daños ambientales ${ }^{22}$ causados por siniestros nucleares y las consiguientes medidas de restauración ${ }^{23}$. Ello a pesar de que la Ley $26 / 2007$, de responsabilidad ambiental, excluye las radiaciones ionizantes, remitiendo a la respectiva regulación sectorial en materia de energía nuclear. Ahora en cambio, la ley aprobada determina que tales daños ambientales, en el caso de ser causados por radiaciones ionizantes en el que se vean involucrados materiales radiactivos que no sean sustancias nucleares, se regirán por lo establecido en la legislación vigente en materia de responsabilidad medioambiental. En el caso de sustancias nucleares sigue siendo la regulación prevista en la legislación sectorial nuclear, ahora la Ley I2/20II, la que regula la restauración de los daños ambientales incluidos dentro del concepto de daño nuclear.

La acción de reclamación prescribe a los tres años a contar desde el momento en que el perjudicado tuvo conocimiento del daño nuclear y del explotador responsable, o bien desde el momento que debió razonablemente tener conocimiento de ello siempre y cuando no se superen los plazos de treinta años para los daños a personas y de diez para daños al medio ambiente y a las cosas a contar desde el accidente nuclear, en la actualidad era de io años para todos los supuestos.

Hasta ahora los convenios obligan a cubrir hasta 700 millones de euros por accidente y de 700 a 1200 los aseguraba el Estado. A partir de ahora el Estado asegurará un margen de hasta 1500 millones. No obstante, pensemos que un accidente nuclear supera en daños los

\footnotetext{
${ }^{22}$ Estos ya se encontraban cubiertos por la ahora derogada disposición adicional segunda de la Ley I7/2007 de 4 de julio, en la que se establecía un régimen transitorio de responsabilidad civil nuclear por daños medioambientales con una cobertura obligatoria de una cobertura de riesgo de 700 millones de euros.

${ }_{23}$ «Medidas de restauración»: Todas las medidas razonables aprobadas por el Ministerio de Medio Ambiente, previo informe del Consejo de Seguridad Nuclear, y que tiendan a restaurar o restablecer los elementos dañados o destruidos del medioambiente o a introducir, cuando esto sea razonable, el equivalente de estos elementos en el medio ambiente.
} 
I500 millones: ¿quién respondería? Pues seguramente el Estado como responsable civil subsidiario, ya que no existe una responsabilidad ilimitada del operador ${ }^{24}$.

Quizá el mayor problema en estos casos sea la dificultad encontrar póliza en el mercado asegurador. En la actualidad, la parte del explotador se cubre mediante un pool atómico español denominado Aseguradores de riesgos nucleares, que agrupa a 33 compañías.

La Ley establece una prelación de las reclamaciones, de manera que se da prioridad a las reclamaciones por daños personales que se formulen dentro de los tres primeros años desde la fecha en la que se produjo el accidente, las cuales deben atenderse sin demora. En segundo lugar, tendrán preferencia las reclamaciones por los daños que sean consecuencia de la degradación del medio ambiente que se formulen dentro de los tres primeros años y seguidamente las reclamaciones formuladas por los daños a los bienes, por las pérdidas económicas derivadas de los daños a las personas y a los bienes, así como por el lucro cesante directamente relacionado con el uso y disfrute del medio ambiente, también dentro de los tres primeros años. A partir del tercer año queda extinguida la prelación, debiéndose atender las reclamaciones por su orden de presentación, hasta el agotamiento de la cuantía máxima establecida en la ley para la compensación de los daños. En caso de que los fondos necesarios para hacer frente a las reclamaciones por daños personales superasen la cuantía máxima establecida, el Estado se obliga a arbitrar los medios legales para compensar a las víctimas ocurridas dentro de España.

\section{V.3. La Ley 8/20II, de infraestructuras críticas}

La entrada en vigor de la Directiva 2008/ıi4, del Consejo, de 8 de diciembre, sobre la identificación y designación de Infraestructuras Críticas Europeas y la evaluación de la necesidad de mejorar su protección, establece que la responsabilidad principal y última de proteger las infraestructuras críticas europeas corresponde a los Estados miembros y a los operadores de las mismas, y se determina el desarrollo de una serie de obligaciones y de actuaciones por dichos Estados, que deben incorporarse a las legislaciones nacionales.

La Ley 8/20II, de infraestructuras críticas transpone esta Directiva. En el artículo 3.b) se señala que la presente Ley se aplica sin perjuicio de los «criterios y disposiciones contenidos en la Ley 25/1964, de 29 de abril, sobre energía nuclear, y normas de desarrollo de la misma, y en la Ley I5/1980, de 22 de abril, de creación del Consejo de Seguridad Nuclear, reformada por la Ley 33/2007, de 7 de noviembre». Por tanto, las instalaciones nucleares están dentro de su ámbito de aplicación.

Esta Ley, como destaca en su artículo I, tiene por objeto establecer las estrategias y las estructuras adecuadas que permitan dirigir y coordinar las actuaciones de los distintos órganos de las Administraciones Públicas en materia de protección de infraestructuras críticas, previa identificación y designación de las mismas, para mejorar la prevención, preparación y respuesta frente a atentados terroristas $u$ otras amenazas que afecten a infraestructuras críticas. Para ello propone la colaboración e implicación de los organismos gestores y propietarios de dichas infraestructuras, a fin de optimizar el grado de protección de éstas contra ataques deliberados de todo tipo a la población.

La Ley define las infraestructuras críticas como aquellas infraestructuras estratégicas cuyo funcionamiento es indispensable y no permite soluciones alternativas, por lo que su perturbación o destrucción tendría un grave impacto sobre los servicios esenciales. Obviamente, entre estas infraestructuras críticas se encuentran las centrales nucleares.

${ }^{24}$ En el debate de la ley, el grupo de IU/Els Verds planteaba con cierta lógica que la responsabilidad de los titulares fuese ilimitada como en Alemania, Suiza o Ucrania. 
La ley articula los diferentes Planes que deben elaborar tanto las Administraciones Públicas (Plan Nacional de Protección de las Infraestructuras Críticas, los Planes Estratégicos Sectoriales y los Planes de Apoyo Operativo) como las empresas, organizaciones o instituciones clasificadas como operadores críticos (Planes de Seguridad del Operador y los Planes de Protección Específicos). Define los análisis de riesgos necesarios de estas infraestructuras así como el estudio de las hipótesis de amenazas posibles, necesario para determinar y evaluar las vulnerabilidades existentes en los diferentes sectores estratégicos y las posibles repercusiones de la perturbación o destrucción de las infraestructuras que les dan apoyo.

Se crea la Comisión Nacional para la Protección de las Infraestructuras Críticas como órgano colegiado adscrito a la Secretaría de Estado de Seguridad. Evidentemente, en su Anexo incluye un listado de sectores estratégico entre los que incluye la industria nuclear y los órganos asignados son el CSN y el Ministerio de Industria y Energía.

Todas estas previsiones han sido desarrolladas por el Real Decreto 704/20II, de 20 de mayo, de infraestructuras críticas, si bien en lo referente a las instalaciones nucleares, remite a su regulación específica ya prevista. Así, se señala en su artículo 29.2 que «Las instalaciones Nucleares e Instalaciones Radiactivas que se consideren críticas reguladas en el Reglamento sobre instalaciones nucleares y radiactivas, integrarán sus Planes de Protección Específicos en los respectivos Planes de Protección Física rigiéndose, en lo relativo a su aprobación y evaluación, por lo establecido en su normativa sectorial específica, sin perjuicio de lo que le sea de aplicación según la Ley 8/20II, de 28 de abril».

\section{V.4. El Real Decreto I308/20II, sobre protección física de instalaciones y materiales nucleares}

Queda claro que en nuestro ordenamiento la responsabilidad sobre la seguridad interior de funcionamiento de las centrales nucleares corresponde al titular de las mismas, al explotador. El titular de una autorización de protección física es responsable de aplicar las medidas de protección, control y vigilancia. Tras las amenazas terroristas posteriores al II-S y, en el caso de España, al II-M, una de las cuestiones que se ha planteado es la protección de la seguridad de las centrales nucleares frente a ataques terroristas. Dadas las peculiaridades de estos materiales radiactivos y nucleares, el concepto de seguridad en las instalaciones en las que son utilizados se extiende a impedir que estas instalaciones o materiales puedan ser objeto de sabotaje, robo o desvío para uso indebido.

La Convención sobre la protección física de los materiales nucleares, adoptada en Viena el 26 de octubre de I979, constituye el régimen internacional para la lucha contra los delitos asociados con las tecnologías y materiales nucleares. La Convención sobre la protección física de los materiales nucleares, hecha en Viena y Nueva York el 3 de marzo de i980, entró en vigor el 8 de febrero de I987 y fue firmada por España en Viena el 7 de abril de 1986 y ratificada, como Estado miembro del EURATOM, el 6 de septiembre de I991. En España, el Real Decreto I58/1995 de 3 de febrero sobre protección física de los materiales nucleares, llevó a cabo la aplicación de la Convención a nuestro ordenamiento, sometiendo a autorización previa otorgada por el Ministerio de Industria, con los informes previos del Ministerio del Interior y del Consejo de Seguridad Nuclear, el ejercicio de actividades de manipulación, procesado, almacenamiento y transporte de los materiales nucleares.

Con el fin de reforzar la seguridad, entre otras, de las instalaciones nucleares, el Consejo de Ministros ha aprobado recientemente este Real Decreto de 23 de septiembre de 20II, mediante el que España adapta a la normativa española de protección de materiales nucleares los compromisos adoptados en la última Enmienda introducida en la Convención sobre la protección física de los materiales nucleares en julio de 2005. Los Estados integrantes de la Convención se comprometieron a reforzar de forma sustancial los controles sobre estos materiales. 
Así el Real Decreto tiene por finalidad:

- Proteger a las instalaciones nucleares, los materiales nucleares y las fuentes radiactivas contra el sabotaje o cualquier otra actuación ilegal que pueda tener consecuencias radiológicas o perjudicar o alterar el normal funcionamiento de las instalaciones.

- Mitigar o reducir al mínimo las consecuencias radiológicas de un sabotaje.

Para el cumplimiento de estos fines, el proyecto de norma determina las competencias del Ministerio de Industria, del Ministerio de Interior y del Consejo de Seguridad Nuclear.

Entre los objetivos de este Real Decreto se destaca la delimitación de forma más concreta de las obligaciones básicas de los titulares de las autorizaciones de protección física, tanto en lo que se refiere al control y la protección de los materiales, instalaciones y transportes sujetos a la reglamentación, como a los criterios de clasificación de seguridad del personal de las instalaciones y transportes y las medidas generales de protección física.

V.5. Las nuevas exigencias de seguridad tras Fukushima. Nuevos «stress test» demuestran que aún se puede mejorar en seguridad

Tras el accidente de Fukushima, puede afirmarse que el largo proceso de rehabilitación de la energía nuclear llevado a cabo en los últimos 25 años tras el incidente de Chernobil se ha venido abajo. Este reciente accidente ha derrumbado el mito de la seguridad, de la racionalidad técnica aplicada al funcionamiento de las centrales.

En las Conclusiones del Consejo Europeo de 24 y 25 de marzo de 20II, primer Consejo posterior al incidente de la central japonesa, la UE puso de relieve la necesidad de aprender cuanto se pueda de estos acontecimientos y de facilitar al público toda la información necesaria. Recordando una vez más que la combinación de fuentes de energía es competencia de los Estados miembros, destacaron la necesidad de revisar la seguridad de todas las centrales nucleares de la UE, sobre la base de una evaluación completa y transparente del riesgo y la seguridad («pruebas de resistencia» o «stress test»). Para ello se invitó al Grupo Europeo de Reguladores de la Seguridad Nuclear (ENSREG) y a la Comisión a que definieran a la mayor brevedad el alcance y las modalidades de dichas pruebas en un marco coordinado, a la luz de las enseñanzas extraídas del accidente de Japón y con plena participación de los Estados miembros, haciendo pleno uso del conocimiento experto disponible (procedente, en particular, de la Asociación de Reguladores Nucleares de Europa Occidental).

Asimismo el mismo Consejo decidió aplicar y mejorar en la UE de manera permanente las normas de seguridad nuclear, que deben promoverse asimismo en el plano internacional. Para ello los Estados miembros deben garantizar la plena aplicación de la Directiva sobre la seguridad de las instalaciones nucleares.

Evidentemente, ya nada volverá a ser como antes. Todas las disposiciones están ya en completa revisión con base en la búsqueda de un imposible físico, el riesgo cero, la seguridad absoluta en la operación de las centrales. Y es que según parece aún se puede mejorar la seguridad, de ahí el anuncio de nuevos requisitos y de pruebas de resistencia adicionales en las centrales europeas. Esto es, cuanto menos, curioso. Y esta reflexión tiene su trasfondo jurídico. Siempre se ha afirmado que las centrales eran seguras; ahora resulta que la seguridad se puede aún mejorar. ¿Por qué no se mejoró antes o por qué no se adoptaron las citadas medidas adicionales antes? Ahora resulta que se van a someter las centrales a nuevas pruebas con obligaciones de mejora en seguridad. El futuro de la energía nuclear dependerá de la credibilidad que sean capaces de generar estas nuevas medidas de seguridad que se apliquen tras los test de estrés a los que se van a someter las centrales nucleares. 
Paralelamente a la reunión del Consejo Europeo y tomando con carácter previo la referencia vista en las conclusiones del citado Consejo, la WENRA (Western European Regulators 'Association) tras el accidente de Fukushima decidió elaborar un listado de análisis de riesgos denominados stress test o pruebas de resistencia.

Estos stress test son en el fondo una reevaluación de los márgenes de seguridad de las centrales nucleares. Los plazos contemplados en la propuesta son de 6 meses para que las centrales completen las previsiones y de 3 meses para la evaluación por parte de los reguladores.

Las pruebas de resistencia se basarán en la evaluación de una serie de aspectos: configurando un auténtico mapa de riesgo. Estos aspectos del risk map son:

a) Sucesos iniciadores: Terremotos e inundaciones superiores al de base de diseño y otras condiciones externas extremas dependiendo de las características del emplazamiento.

b) Pérdida de las funciones de seguridad: Pérdida total prolongada de suministro eléctrico ${ }^{25} \mathrm{y}$ del sumidero final de calor.

c) Problemas de gestión del accidente ante un accidente con fusión del núcleo, incluyendo efectos tales como la acumulación de hidrógeno; o condiciones degradadas en el almacenamiento del combustible gastado, incluyendo efectos como la pérdida de blindaje contra la radiación.

Una vez más, la exigencia de transparencia y publicidad en este ámbito deberá conllevar necesariamente que los resultados de estas pruebas de estrés de todas las centrales nucleares sean, además de rigurosos, públicos, y que se examinen no sólo los riesgos frente a catástrofes naturales, sino también frente a accidentes y terrorismo. Todo esto recuerda bastante al sector financiero, que era sólido y fiable, se le hicieron unas pruebas de estrés que superaron prácticamente todas las entidades y, a pesar de ello, no parece haber llegado la estabilidad al sistema financiero.

En España, el 25 de mayo de 201 I el CSN aprobó las pruebas de resistencia para inundación, terremoto, accidente severo o pérdida de refrigeración, implementando así las exigencias derivadas de los denominados test de estrés, aprobados tras el accidente de Fukushima. En el seno de la UE no fue posible alcanzar un consenso inicial para incluir dentro de estas pruebas de resistencia los ataques terroristas o el impacto de aeronaves, lo que definitivamente se dejó en manos de los Estados miembros. Paralelamente, el Congreso español aprobó por unanimidad el 20 de abril de $20 \mathrm{II}^{26}$ una proposición no de ley en la que solicitaba al CSN que introdujese dentro de los test, el análisis de resistencia de las instalaciones nucleares frente a posibles ataques terroristas y sabotajes o ciberataques, así como la resistencia de los sistemas de contención ante el impacto de aeronaves. Tomando en consideración esta proposición no de ley del Congreso, el CSN aprobó el pasado 30 de junio de 20II una nueva Instrucción Técnica Complementaria lo que hará que sin duda la superación de las pruebas por todas las centrales nucleares españolas sea más complicada. Esta ITC establece los requisitos para mitigar las consecuencias de un ataque externo en las centrales nucleares.

\footnotetext{
${ }^{25}$ Recientemente el CSN y Red Eléctrica Española han creado un grupo de trabajo para colaborar conjuntamente en la seguridad de las centrales nucleares españolas analizando el refuerzo de los sistemas de alimentación eléctrica para garantizar su funcionamiento en el caso de que se produjera un fallo en el suministro eléctrico. Todo ello con el fin de preparar los equipos para el momento en que se aprueben por la UE los stress-test.

${ }^{26}$ Proposición no de Ley ante el Pleno sobre la seguridad de las centrales nucleares españolas. (I62/000828) presentada el 25/03/20II y aprobada por el Pleno el 20 de abril (BOCG, serie D, núm.560, de 20 de abril, p.I3-I4).
} 
El proceso que las centrales nucleares españolas deben seguir de acuerdo con esta nueva ITC es el siguiente: antes del 3i de diciembre de 20 II el titular de la central debe enviar al CSN un análisis que contenga el estudio de las acciones que se incluyen en la ITC, así como una propuesta de las medidas a implantar; antes del 3i de diciembre de 20I2, el titular de la central debe haber implantado todas las medidas resultantes de la aplicación de esta ITC. En concreto, el operador de la central deberá definir las medidas y metodología ante los siguientes supuestos:

- mitigación de sucesos más allá de la base de diseño, como el impacto de un avión comercial.

- mitigación de explosiones y fuegos de gran tamaño y larga duración, de más de 48 horas.

- garantizar respuestas coordinadas ante situaciones de emergencia.

Con la segunda ITC posterior a los incidentes de Fukushima, el CSN va más allá en cuanto a las exigencias que las establecidas por la WENRA (Western European Nuclear Regulators Association) y por ENSREG (European Nuclear Safety Regulators Group).

De acuerdo con lo previsto, a mediados de agosto de 20II, el CSN recibió los informes preliminares de los titulares de las centrales nucleares españolas con los resultados iniciales de las pruebas de resistencia, siguiendo el calendario establecido por el organismo regulador español en coordinación con los demás reguladores europeos.

El I5 de septiembre el CSN envió a la Comisión Europea un informe preliminar con su análisis inicial sobre la documentación remitida por las instalaciones nucleares y posteriormente, el 3I de octubre, las empresas operadoras de las centrales enviarán al Consejo los resultados completos de las pruebas, así como la documentación de soporte correspondiente. Por último, el CSN deberá enviar a la Comisión Europea su informe definitivo, antes del 3I de diciembre del presente año 20II.

Obviamente, los resultados obtenidos de estas pruebas de estrés se incorporan en los requerimientos para próximas autorizaciones de explotación.

El CSN ha constatado en su dictamen remitido a Bruselas que los informes preliminares de las centrales nucleares españolas cumplen con las especificaciones de la Asociación de Reguladores Nucleares de Europa Occidental (WENRA) y del Grupo Europeo de Reguladores de Seguridad Nuclear (ENSREG), así como las Instrucciones Técnicas Complementarias (ITC) aprobadas por el propio CSN.

La Comisión Europea ha confirmado que ha recibido los informes preliminares de todos los reguladores nacionales de los Veintisiete de las pruebas de resistencia que se han efectuado a las I43 plantas nucleares en los I4 Estados miembros que albergan reactores. Ha avanzado que presentará su propio informe preliminar de las pruebas el próximo 9 de diciembre y su informe final en junio de 2012 .

\section{El marco normativo de la gestión de los residuos radiactivos en España}

Uno de los principales problemas de la energía nuclear consiste en la gestión adecuada de los residuos radiactivos y en la clausura de las instalaciones ${ }^{27}$. Un legado para

\footnotetext{
${ }^{27}$ Sobre esta cuestión Sánchez Guitián, M.N. (2006), De la Cruz Ferrer, J. (2009) y Ruiz de Apodaca Espinosa, A. (2009).
} 
las generaciones venideras y una cuestión de actualidad en España donde su gestión está reservada en exclusiva al Estado como servicio de interés general. Sobre esta cuestión volveremos en profundidad al hilo del procedimiento para la instalación del ATC. Como señala Santamaría Arinas (2009, II6), tenemos un Derecho para una sociedad nuclearizada, si bien el Derecho es una herramienta de eficacia limitada y que la gestión del riesgo no es el único reto que se plantea en los estados que dicen asumir el denominado desarrollo sostenible, sin duda pensando en el peligroso legado que suponen los residuos radiactivos.

Ahora bien, hablamos de Derecho ambiental y por tanto de desarrollo sostenible, aquel modelo de desarrollo que satisfaciendo las necesidades de las generaciones presentes no comprometa el desarrollo de las generaciones venideras. El profesor Loperena $(2010,20)$ propone una ética para la crisis, «es una inmoralidad dejar a nuestros nietos toneladas de residuos peligrosísimos que nosotros no sabemos tratar y ellos probablemente tampoco. ¿Podemos dejar un mundo lleno de residuos radiactivos exigiendo que inventen ellos la forma de eliminarlos?».

Como se ha señalado, la generación de energía a partir de fuentes de energía nuclear nos coloca una vez más en la conocida dinámica problema-solución-nuevo problema. Estamos ante una ineludible concatenación de decisiones que requiere como señala Esteve Pardo (2009, 35), «la admisión de la energía nuclear y sus riesgos hace incuestionable la posterior decisión sobre el emplazamiento de las centrales y, posteriormente, de las plantas de tratamiento o almacenaje de residuos nucleares».

En este punto se pierde algo de vista el concepto de desarrollo sostenible y hay algo en ello de fiar decisiones político-jurídicas a los futuros e inciertos logros de la ciencia y la tecnología. El creer que el desarrollo científico en un futuro solucionará la gestión de los residuos nucleares (sin tener esa certeza de ninguna manera en el presente) no puede condicionar una decisión política en sentido favorable; de actuar así estaríamos ante una posición de claro antropocentrismo tecnocrático ${ }^{28}$ y de radical insolidaridad con las generaciones venideras. Es más, las expectativas de la evolución científica como elemento relevante a la hora de adoptar decisiones constituye la introducción de un nuevo elemento de riesgo, de una nueva incertidumbre en la toma de decisiones (Esteve Pardo 2009, 35, 45-46 y II4-II5', en definitiva, de una apuesta de elevado riesgo.

\section{VI.I. La gestión en España de los residuos radiactivos}

La gestión de los residuos radiactivos en España está reservada en exclusiva al Estado como servicio de interés general y se lleva a cabo por ENRESA. Esta gestión está presidida por tres principios: a) que los costes sean soportados por los generadores; b) que la gestión obedezca a una planificación realista y a largo plazo, y c) que la gestión se someta a una serie de controles tanto técnicos como económicos ${ }^{29}$.

La situación en España en lo que se refiere a la gestión de los residuos de baja y media actividad, como es sabido, se lleva a cabo en el almacén de residuos radiactivos de baja y media actividad que ENRESA gestiona en El Cabril y que recientemente se ha autorizado su ampliación para residuos de muy baja actividad ${ }^{30}$.

\footnotetext{
${ }^{28}$ Sobre esta corriente aparentemente disparata de la que nuestra sociedad desarrollada está realmente más cerca de lo que creemos, Ballesteros, J. (i995).

${ }^{29}$ Estos tres obvios principios extrapolables a la gestión de cualquier familia de residuos son predicables respecto de los residuos radiactivos por Arias Cañete, A. (I988, 99-IoI).

$3^{\circ}$ Resolución de 2I de julio de 2008, de la Dirección General de Política Energética y Minas, por la que se autoriza a ENRESA la modificación de diseño de la instalación nuclear de almacenamiento de residuos
} 
En lo que interesa respecto a la gestión del combustible gastado de las centrales nucleares, esta gestión en España se llevó inicialmente a cabo mediante el sistema de ciclo cerrado, reprocesándose el combustible gastado de las centrales de Vandellós I, José Cabrera (Zorita) y Santa $\mathrm{M}^{a}$ de Garoña. Esta práctica se interrumpió en I982, salvo para la primera de estas centrales, que dejó de operar en el año ig89 y cuyo combustible tuvo que ser reprocesado en su totalidad ${ }^{3 \mathrm{I}}$.

Desde entonces se opta por el ciclo abierto, previo almacenamiento en las piscinas de las centrales del combustible gastado. El problema radica en la saturación prevista de la capacidad de estas piscinas. Si bien, a lo largo de la década de los noventa, se acometió la progresiva sustitución de los bastidores originales por otros más compactos, lo que ha permitido, en la mayoría de los casos, diferir notablemente en el tiempo la necesidad de dotar al sistema español de una capacidad de almacenamiento adicional a la de las propias piscinas. No es necesaria autorización en caso de almacenamiento on site en las propias piscinas de las centrales nucleares, como se ha encargado de confirmar la STS de 24 de noviembre de 2009 , sobre necesidad de nuevas autorizaciones para almacenamiento on site del combustible gastado en las propias centrales nucleares ${ }^{32}$.

Un caso singular es el de la Central Nuclear de Trillo que agotó su capacidad de almacenamiento en el año 2003 teniendo que optarse por almacenar su combustible gastado en contenedores metálicos y alojándolos en un almacén construido en el propio emplazamiento de la central y operativo desde 2002. La construcción de este ATI en la Central Nuclear de Trillo no estuvo exenta de cierta conflictividad, dando lugar a sucesivas sentencias que han sido ampliamente comentadas y a las que haremos referencia más adelante.

Actualmente, las necesidades de almacenamiento temporal adicional de combustible gastado, vienen dictadas por la Central Nuclear José Cabrera (descarga de ioo tU a un almacén temporal para permitir el inicio del desmantelamiento de esta central hacia el año 2009), y por la saturación de las piscinas de varias centrales (Ascó i y 2 y Cofrentes) que se producirá en torno a los años 20I3-20I4. Se calcula que para 2030 en España habrá en torno a 6.700 toneladas de residuos radiactivos de alta actividad.

radiactivos sólidos de Sierra Albarrana (El Cabril), para el almacenamiento de residuos radiactivos de muy baja actividad publicada en el BOE núm. I95 de I3.08.2008.

${ }^{31}$ Como consecuencia de los compromisos derivados de los diferentes contratos de reprocesado, debían retornar a España diversos residuos de media y alta actividad resultantes del reprocesado del combustible de Vandellós I en Francia que deberán volver a España entre los años 2010 y 20I5, existiendo fuertes penalizaciones económicas si el primer transporte no tenía lugar antes del 3i de diciembre de 20Io. Igualmente los materiales energéticos (uranio y plutonio) recuperados en el reprocesado en Reino Unido del combustible de Garoña han debido ya regresar en 2008 (plutonio) y lo debían hacer antes de 20II (uranio).

${ }^{32}$ La cuestión de fondo de la sentencia se basa en la pretensión de AMAC de que las centrales nucleares citadas contasen con nuevas autorizaciones, distintas de las originarias de funcionamiento y sus modificaciones, para el almacenamiento temporal y enfriamiento del combustible gastado en sus piscinas, al entender que la autorización inicial de funcionamiento no ampara tales operaciones (al haberse ampliado la capacidad de tales piscinas mediante nuevos bastidores de almacenamiento compacto que sustituirían a los existentes). AMAC sostiene que la ampliación de la capacidad de almacenamiento de las piscinas de las centrales nucleares para mantener en ellas los residuos radioactivos de las propias centrales sobre la base de las licencias iniciales otorgadas en su día para cada una de las centrales nucleares se ha efectuado de forma contraria a derecho, por no contar con las autorizaciones exigibles por la Ley de Energía Nuclear, vulnerándola. El TSJ de Madrid y, ulteriormente, el TS, entienden, al igual que la Dirección General de Energía Nuclear, la innecesariedad de nuevas autorizaciones, dado que la propia autorización inicial de funcionamiento de las centrales nucleares implica la necesidad de hacer frente al almacenamiento temporal y enfriamiento del combustible gastado en sus respectivas piscinas hasta su traslado a emplazamientos definitivos. 


\section{VI.2. El Plan de Gestión de los Residuos Radiactivos (PGRR)}

De acuerdo con la Disposición Adicional Sexta bis de la LSE 54/1997, corresponde al Gobierno establecer la política sobre gestión de residuos radiactivos y desmantelamiento y clausura de las instalaciones nucleares y radiactivas mediante la aprobación del Plan General de Residuos Radiactivos, que será elevado por el Ministerio de Industria, Turismo y Comercio, una vez oídas las Comunidades Autónomas con competencias en materia de ordenación del territorio y medio ambiente, y del que dará cuenta posteriormente a las Cortes Generales.

El PGRR es un instrumento fundamental en la planificación respecto a la gestión de los residuos radiactivos que se generan en España. Su contenido hace referencia a las estrategias, actuaciones y soluciones técnicas de gestión de los residuos radiactivos al corto y medio plazo con base en las previsiones de desmantelamiento y clausura de instalaciones nucleares y radiactivas. Igualmente incluye las previsiones económicas y financieras para llevar a cabo las citadas estrategias y la necesaria gestión.

El Plan es elaborado por ENRESA y enviado al Ministerio de Industria cada cuatro años, siendo finalmente aprobado por el Gobierno, que es a quién finalmente corresponden las decisiones sobre la política nuclear y más concretamente las decisiones sobre gestión de residuos radiactivos y desmantelamiento y clausura de instalaciones nucleares y radiactivas.

El vigente Sexto Plan fue aprobado por el Consejo de Ministros 23 de junio de 2006, que sustituyó y revisó el Quinto Plan anteriormente aprobado en julio de I999. Los anteriores PGRR han ido estableciendo distintas estrategias en función de las diferentes soluciones existentes y las opciones políticas en materia de gestión de residuos, si bien todos ellos han previsto como solución definitiva el almacenamiento geológico profundo y la construcción de un almacén temporal centralizado (sin que a día de hoy ni una ni otra solución se hayan adoptado en España $\left.{ }^{33}\right)$. Antes de analizar las previsiones del actual PGRR es necesario hacer referencia a su obligatoriedad o poder vinculante para la propia Administración que lo aprueba (en este caso, el Consejo de Ministros). Bajo mi punto de vista, si bien los planes no tienen a priori un carácter normativo, vinculan y obligan a la Administración autora de la misma a adoptar todos los medios necesarios para su cumplimiento. Es más, sabemos de la existencia de algunos planes que sí son aprobados mediante norma jurídica reglamentaria o incluso legal. Nada obsta entonces para que los que son aprobados mediante resolución del Consejo de Ministros tengan también cierta eficacia vinculante para los destinatarios y para la propia Administración autora del mismo ${ }^{34}$.

Para cumplimiento del objetivo primordial previsto en el PGRR consistente en la construcción de un ATC, la Comisión del Congreso de Industria, Turismo y Comercio aprobó en su sesión de 27 de abril de 2006 una Proposición no de Ley relativa al establecimiento de una comisión interministerial encargada de establecer los criterios que debería cumplir el emplazamiento del almacén temporal centralizado de combustible nuclear gastado y residuos de alta actividad, y de su centro tecnológico asociado. Cumpliendo este mandato del Congreso, el Gobierno mediante el Real Decreto 775/2006, de 23 de junio, creó la Comisión Interministerial para coordinar las actuaciones tendentes a la instalación y creación de un Almacén Temporal Centralizado de Residuos Radiactivos.

Sin duda alguna uno de los principales problemas vuelve a ser el conocido efecto «NIMBY» y los problemas que plantea el rechazo vecinal a la implantación de este tipo de

\footnotetext{
${ }^{33}$ Sobre las previsiones de los diferentes PGRR aprobados en España, Barceló, A. (2002, I77-I83).

34 En este punto discrepo de Ayllón Díaz-González, J.M. (I999, I86), Barceló Barceló, A. (2002, I84) y Del Olmo Alonso, J. $(2002,69)$, ya que califican los PGRR de meras memorias de una empresa pública dedicadas a comunicar sus actividades al Gobierno para recibir su aprobación, careciendo de valor normativo y del privilegio de vinculación de las normas al no haberse producido el procedimiento de aprobación y publicación previsto para las disposiciones generales.
} 
infraestructuras por otro lado absolutamente necesarias ${ }^{35}$. El problema ahí está y el Organismo Internacional para la Energía Atómica (OIEA) en la evaluación global llevada a cabo recientemente del sistema nuclear español, ha recomendado construir un centro de almacenamiento de residuos de alta intensidad ante la inexistencia en España de una solución final ${ }^{36}$.

\section{VI.3. El actual procedimiento para la instalación de un Almacén Temporal Centralizado} (ATC)

Así las cosas, llegamos a un nuevo problema al que hay que dar solución sí o sí. Nos encontramos como decía ante un procedimiento prospectivo de clara distribución territorial del riesgo en España ${ }^{37}$.

La etapa más importante del procedimiento autorizatorio es evidentemente la correspondiente decisión sobre su emplazamiento ${ }^{38}$ y también la principal dificultad ${ }^{39}$. En el procedimiento de autorización de emplazamiento regulado en el RINR se prevé un trámite de información pública, que en su caso será común con el de EIA. Pero la previa elección de un emplazamiento para albergar residuos radiactivos exige un procedimiento participativo, transparente de todos los afectados. Para evitar el efecto NIMBY (Not in my back yard), quizá inevitable, el propio PGRR establecía la necesidad de procedimientos de información y participación que facilitasen la obtención del consenso político y social necesario para decidir su emplazamiento. Es evidente que las Administraciones competentes en la toma de decisiones deben tener un papel fundamental para garantizar la transparencia de la información y diálogo y participación abierta de los ciudadanos. Es por tanto imperiosa la necesidad de comunicar a la sociedad y a sus representantes más significativos la realidad presente y perspectivas de futuro en materia de gestión de residuos radiactivos. Así el público podrá entender mejor los procesos y percibirá los riesgos desde una óptica más racional y menos emocional. Por otro lado el régimen de compensaciones ${ }^{40}$ que se establezca al municipio que lo acoja en su territorio quizá pudiera hacer atractivo su emplazamiento a los vecinos.

La ubicación de instalaciones nucleares se ha venido centrando hasta nuestros días en aspectos exclusivamente técnicos, económicos y competenciales ${ }^{4 \mathrm{I}}$, relegando otras consideraciones éticas, sociales y políticas. La elección de un emplazamiento para este tipo de instalaciones implica aspectos de carácter ambiental, planteamiento urbano y regional, equidad

\footnotetext{
35 Tema muy recurrente en todas y cada una de las instalaciones y proyectos con incidencia sobre el medio ambiente. La existencia de este efecto ha sido citada y analizada profusamente jurídica y sociológicamente en España y en otros países. Ya lo pusieron de manifiesto O’Hare, M. (I977), Allende Landa, J. (I984) y, por supuesto, Martín Mateo, R. (I992, 734-735).

${ }^{36}$ Los resultados aproximados de la misión International Regulatory Review System (IRRS) de la OIEA pueden conocerse a través de la comparecencia de la presidenta del CSN ante la Comisión de Industria, Turismo y Comercio de 26 de noviembre de 2008 publicada en el Diario de Sesiones del Congreso núm. I58.

37 El procedimiento que en España se ha llevado a cabo para determinar por parte del Gobierno la ubicación aún no decidida del ATC es objeto de furibunda crítica en Sosa Wagner, F. y Fuertes, M. (20II, 4I-70).

${ }^{38}$ Martín Mateo, R. (I982, 349). Los problemas relacionados con el emplazamiento de las instalaciones nucleares son los que han venido dando lugar a la conflictividad de estas instalaciones y las que han dado lugar a los diferentes pronunciamientos jurisprudenciales.

${ }^{39}$ Algo puesto de manifiesto ya hace muchos años por el Prof. Martín Mateo (I992, 739).

$4^{\circ}$ Sobre el régimen de compensaciones arbitrado a los municipios por el emplazamiento de residuos radiactivos, Ayllón Díaz-González, J.M. (I999, I80-I83).

${ }^{4 \mathrm{I}}$ El TC ya ha tenido ocasión en la STC I4/2004 de I2 de febrero, de señalar la competencia exclusiva del Estado sobre esta cuestión al hilo de un recurso planteado contra la Ley I7/1998, de ordenación del territorio de Aragón, sobre esta cuestión. Cfr. Fortes Martín, A. (2004).
} 
espacial, equilibrio territorial, coste de la energía y, sobre todo, riesgos y densidad poblacional. Ello supone que necesariamente ha de politizarse el proceso de ubicación de este tipo de instalaciones, haciendo el procedimiento participativo y abierto, buscando la negociación con todos los participantes aunque ello alargue el procedimiento y las deliberaciones sobre la ubicación ${ }^{42}$. La ausencia de una dimensión participativa, plural, de un consenso institucional, político y territorial viciaría claramente este tipo de decisiones e iría en contra de los principios de gobernanza si bien, para Sosa Wagner y Fuertes, la gobernanza en este procedimiento es una auténtica calavera que no ha dado lugar más que a una serie de sucesivas reuniones sin ningún progreso (Sosa Wagner, F. y Fuertes, M. 20II, 54-56).

La implementación de soluciones a la gestión de los residuos radiactivos y la elección de su emplazamiento exige un compromiso político a largo plazo, conceptos de gobernanza modernos, basados en un enfoque gradual, y la implicación desde el principio de los sectores interesados nacionales y locales para garantizar unas consultas válidas, la participación y la aceptación del público. Este tipo de conceptos de gobernanza modernos son los que forman la base del éxito. No obstante, con independencia de que se dé información, plena transparencia y se presenten concienzudos análisis de riesgo, el miedo es libre, y el rechazo vecinal a la implantación de este tipo de instalaciones suele ser total. Así, al citado efecto NIMBY se le han sumado el también inglés efecto BANANA (Built absolutely nothing anywhere near anything), Greenberg (2009, I242); y la versión española denominada efecto SPAN (Sí, pero aquí no). Al hilo del ATC además y dado el curso político en el que nos encontramos habría que sumar un acrónimo más: NIMEY (No In My Election Year), causa del retraso en la decisión de un Gobierno presionado sin duda en cada uno de los territorios en los que se ubican los municipios que han presentado candidatura.

La Comisión Interministerial encargada del proceso de selección del emplazamiento del ATC y su Centro Tecnológico asociado, inició en julio de 2006 un periodo informativo que se prolongó hasta el 28 de febrero de 2007. La perentoriedad de la ATC se explica no sólo por el hecho de que las piscinas de nuestras centrales nucleares para enfriamiento del combustible gastado tienen una limitación, sino por el elevado coste de 60.000 euros/día que, desde enero de 20II, supone para ENRESA la gestión del combustible de la central de Vandellós I (clausurada en I989) y que se encuentra ahora mismo en Francia. Si se multiplica por un año la cifra es de 22 millones de euros, y si se multiplica por tres (consecuencia del retraso a día de hoy en la toma de decisión y construcción del almacén) la cifra alcanza los 66 millones, el ıo\% del coste total del ATC que se estima en 600 millones de euros ${ }^{43}$. En este marco, las perentorias necesidades que se están dando en distintas centrales nucleares españolas está llevando a que de facto se esté optando por Almacenes Temporales Individuales (ATI) anejos a las propias centrales que generan estos residuos. En España hay dos Almacenes de Residuos Radiactivos de alta actividad (Trillo y Zorita) y ya se pretende construir un tercero en Ascó ${ }^{44}$. El PGRR apuesta como hemos visto por la solución de un ATC con base en consideraciones estratégicas, económicas y de seguridad, no contemplando Almacenes Temporales Individuales (ATI) como alternativa al ATC, aunque su demora está forzando que se opte por la solución individualizada.

${ }^{42}$ Allende Landa, J. (I984, I39). Sobre la ubicación de instalaciones nucleares véase también Sosa Wagner, F. (I978).

${ }^{43}$ Así lo señalan Sosa Wagner F. y Fuertes, M. (20II, 63).

${ }^{44}$ Así, en el BOE num. 9I, de I5 de abril de 2008 y bajo resolución con carácter de urgente, se publicaron las bases de la Convocatoria de concurso de la «Empresa Nacional de Residuos Radiactivos, Sociedad Anónima» (ENRESA) para la contratación del diseño, el apoyo al licenciamiento (I. ${ }^{a}$ fase) y el suministro de un sistema de almacenamiento modular transportable en el emplazamiento de la Central Nuclear de Asco-Tarragona (2. ${ }^{a}$ fase). La obra consiste en un almacén en seco para los residuos producidos en dicha central (ATI) y pretenden que pueda estar operativo en febrero de 20 II al igual que ya se hace en Zorita o Trillo (ambos almacenes en Guadalajara). ENRESA contempla que estos contenedores deben ser para el almacenamiento de los residuos en condiciones de seguridad por un periodo de, como mínimo, 50 años. La Secretaria de Estado de Cambio Climático del Ministerio de Medio Ambiente, mediante Resolución de I de septiembre de 20II, formulaba la Declaración de Impacto Ambiental favorable al citado ATI en Ascó (BOE 2I.09.20II). 
Así las cosas, a la vista de la Resolución de 23 de diciembre de 2009, por la que se efectúa la convocatoria pública para la selección de los municipios candidatos a albergar el emplazamiento del Almacén Temporal Centralizado de combustible nuclear gastado y residuos radiactivos de alta actividad (ATC) y su centro tecnológico asociado, no debiera obviarse la importancia que tiene la participación en la toma de este tipo de decisiones.

Resulta llamativo el hecho de que habiendo en España 8iıı municipios, sólo haya 8 candidatos idóneos que hayan presentado candidaturas al emplazamiento del ATC en su respectivo término municipal ${ }^{45}$. De estos 8 municipios, 5 de ellos tienen menos de 500 habitantes y otros tres menos de I500. Ningún otro municipio se ha atrevido a solicitarlo pese a la inversión de 700 millones de euros, la percepción anual de 6 millones de euros para las arcas municipales, el beneficio de crecimiento poblacional y empleo para la zona. Este régimen de compensaciones ${ }^{46}$ al municipio que lo acoja en su territorio hará atractivo su emplazamiento.

Ni que decir tiene que este tipo de emplazamiento está sujeto a EIA, que necesariamente garantiza la participación pública, no pudiendo darse en caso alguno un pronunciamiento como el de la STS de 26 de diciembre de 200I al hilo del recurso contra la autorización del ATI de Trillo que señalaba «es lógica la necesidad de ese estudio previo de evaluación ambiental para toda instalación nuclear de Central o de depósito de residuos nucleares, «ex novo», pero esa necesidad, racionalmente, debe desaparecer, cuando lo proyectado se refiere a un depósito temporal de combustible gastado, a ubicar en la propia Central Nuclear de Trillo, que fue objeto en su día de esa evaluación de impacto ambiental.» Con esta interpretación se eludía la participación pública en la autorización del ATI de Trillo, algo que, a mi juicio, es grave.

En el caso que nos ocupa, la resolución del Ministerio de Industria señala que el emplazamiento de la instalación ATC deberá cumplir con todos los requisitos, trámites y licencias de las diferentes administraciones competentes, entre ellos, los relacionados con la correspondiente evaluación de impacto ambiental, previa a la autorización de las obras de construcción. Como se ha señalado, en este trámite deberá necesariamente darse cabida a la participación pública. Pero surgen algunos interrogantes como qué estudio de alternativas contendrá el estudio de impacto ambiental en cuanto al emplazamiento, si ya se parte de un emplazamiento designado por el Gobierno y no precisamente con base en una previa elección técnica, sino con base en unas candidaturas presentadas por una serie de municipios cuyos plenos han tomado tal decisión por razones de urgencia económica. No parece que ésta sea una buena forma de instrumentar un procedimiento administrativo autorizatorio de gestión de riesgos en el que debe caber el aspecto técnico, científico y también participativo. Quizá debiera haberse circunscrito la elección del emplazamiento al criterio anglosajón denominado CLAMP (Concentrating locations at major plants), Greenberg (2009, I243), es decir, ubicación junto a alguna de las plantas ya existentes. Con este criterio cuenta la candidatura de Ascó ${ }^{47}$.

En cuanto al procedimiento, a mi juicio, la participación ha estado asegurada una vez presentadas las candidaturas y no antes. Buena muestro de ello es la publicidad de las alegaciones presentadas dentro del procedimiento previo a la toma de decisión y la publicidad de las mismas. Presentadas las candidaturas, el Ministerio de Industria publicó en el BOE de 6

\footnotetext{
${ }^{45}$ Estos son Albalá, Ascó, Congosto de Valdavia, Melgar de Arriba, Santervás de Campos, Torrubia de Soria, Villar de Cañas, Yebra y Zarra.

${ }^{46}$ Sobre el régimen de compensaciones arbitrado a los municipios por el emplazamiento de residuos radiactivos, Ayllón Díaz-González, J.M. (I999, I80-I83).

47 En sentido contrario, el informe de 27 de abril del Consejo asesor para el desarrollo sostenible de la Generalitat de Catalunya en el que pide que Ascó y Vandellós vacíen al máximo sus piscinas de combustible gastado para reducir el riesgo de accidente. A la vez solicitaba que se revisasen exhaustivamente dichas piscinas teniendo en cuenta la posible pérdida de refrigeración o eventuales ataques. El mismo informe, en relación con el ATC, establece que éste debiera ubicarse lejos de cualquier central nuclear en activo con el fin de reducir riesgos, aunque reconoce que este criterio es contrario al que maneja el Ministerio de Industria.
} 
de marzo de 20 io un anuncio para que, quien lo desease, pudiera formular observaciones y alegaciones sobre la aplicación de los criterios de la convocatoria a las candidaturas de municipios admitidas, disponiendo para ello de un plazo de tan solo veinte días. Adicionalmente, se notificó individualizadamente a 44 instituciones y entidades, entre ellas, las comunidades autónomas y diputaciones provinciales en cuyo ámbito territorial se encuentran los municipios admitidos, a dichos municipios, a la Federación Española de Municipios y Provincias, así como a aquellas organizaciones y asociaciones cuyos fines guardan relación directa con el objeto del procedimiento ${ }^{48}$ entre ellas las ONGs ecologistas. Entre las citadas organizaciones se encuentra Greenpeace que presentó recurso contencioso-administrativo al que se ha sumado Ecologistas en Acción contra este procedimiento por incumplir el Convenio de Aarhus, relativo a la información, participación y acceso a la justicia en materia ambiental, no citado en ningún documento ni momento del procedimiento. A juicio de la ONG no ha habido mecanismos de participación pública previos al inicio del proceso. El pasado 23 de junio de 20Io, derivado del citado recurso contencioso-administrativo interpuesto por Greenpeace, la Audiencia Nacional ordenó mediante Auto al Ministerio de Industria que incluyese en el expediente que ha de entregarse a la demandante los siguientes documentos: proyecto técnico del ATC, estudio de seguridad, proyecto de centro tecnológico asociado, estudio de seguridad del centro tecnológico y los informes sobre la protección física del emplazamiento. La Abogacía del Estado, se opone a la presentación de los citados informes. A esta petición la Audiencia Nacional ha remitido providencia a Greenpeace comunicando la inexistencia de tales informes de seguridad, por lo que invocan la nulidad del proceso por ser contrario al derecho a la información ambiental. Quizá estos informes, a mi juicio, no sean ahora necesarios. Ahora en lo que se está es una fase de elección de emplazamiento sobre la base de una serie de candidaturas presentadas, una decisión que sigue sin haberse producido.

Tras el estudio de las candidaturas y de las alegaciones, la Comisión Interministerial, asesorada por el Comité Asesor Técnico, elevó al Gobierno una propuesta ordenada de municipios candidatos a albergar la instalación una vez evaluada la idoneidad de los mismos ${ }^{49}$. Tras esta propuesta debía el Gobierno haber decidido el municipio en el que se ubicará esta instalación industrial.

Una vez que el Gobierno adopte la decisión del emplazamiento, se abrirá un nuevo procedimiento en el que nuevamente la participación y la información deben ser garantizadas. Este procedimiento requerirá informe favorable al proyecto por parte del CSN, posterior evaluación de impacto ambiental por parte del Ministerio de Medio Ambiente, las autorizaciones de emplazamiento y explotación del Ministerio de Industria y la licencia de obra del municipio en cuyo término vaya a emplazarse.

A pesar de este procedimiento previsto en el que se pretenden alcanzar altas cotas de consenso político, institucional y territorial, lamentablemente, una vez más, la conflictividad está servida. Ninguna Comunidad Autónoma quiere asumir esta carga. Todos los parlamentos autonómicos y gobiernos de las CCAA en cuyo territorio se ubican los municipios candidatos aprobaron en 2010 mociones de rechazo y en el mismo sentido se han pronunciaron los respectivos gobiernos autonómicos ${ }^{50}$. Como decía al principio nos encontramos ante un fenómeno prospectivo de distribución territorial del riesgo que requiere una solución. Se

\footnotetext{
${ }^{48}$ Como resultado de dicho trámite, se han recibido un total de 14.420 escritos de alegaciones: 735 a través del buzón de correo electrónico establecido al efecto y del registro telemático del Ministerio de Industria, Turismo y Comercio, y el resto a través del registro general.

${ }^{49}$ Según los medios de comunicación los municipios de Zarra y el de Ascó serían los que arrojan la puntuación más elevada dada por el comité técnico. En el caso de Zarra, las Cortes Valencianas aprobaron una moción de rechazo a la implantación del ATC en la Comunidad (todos los demás parlamentos autonómicos ya lo han hecho) y el TSJ de Valencia en septiembre de 2009 anuló la recalificación de los terrenos de Zarra (el plan parcial y el PAI) como industriales por no asegurarse el suministro de agua.

$5^{\circ}$ Relación del iter político procedimental y de estas mociones de rechazo dan cuenta Sosa Wagner, F. y Fuertes, M. (2011, 64-70).
} 
anunciaron recursos judiciales por parte de los Gobiernos respectivos en caso de que el municipio elegido fuese el de su Comunidad Autónoma. Recursos que tendrían difícil su estimación, salvo que la decisión carezca de motivación o no se hayan respetado los elementos reglados o de procedimiento, ya que la decisión es claramente discrecional, lo que hará difícil su revisión. Estos recursos vendrían acompañados de la correspondiente solicitud de medidas cautelares de suspensión mientras no resuelvan y mientras las piscinas a rebosar de combustible gastado en cada una de las CCNN españolas. En consecuencia, ni 20 Io ni $201 \mathrm{I}$ han sido los años del ATC pese a lo previsto en el PGRR, y veremos si lo llega a ser 2012 . Mientras tanto son 60.000 euros diarios los que paga el Estado español a AREVA, a Francia, desde el i de enero de 20 II por los residuos radiactivos de Vandellós I que fue cerrada en ig89.

\section{Bibliografía}

ALLENDE LANDA, J. (I984): «Algunas directrices para una nueva política de ubicación de reactores nucleares», Revista de Estudios Regionales I3.

ARIAS CAÑETE, A. (I988): «Legislación sobre la gestión de los residuos radiactivos», en Jornadas de estudio sobre el presente y futuro de la legislación española en materia de energía nuclear, Madrid.

AYLLÓN DÍAZ-GONZÁLEZ, J.M. (I999): Derecho nuclear, Granada: Comares.

BARCELÓ BARCELÓ, A. (2002): Instalaciones nucleares, autorización y conflicto, Barcelona: Ariel.

BALLESTEROS, J. (I995): Ecologismo personalista: cuidar la naturaleza, cuidar al hombre, Madrid: Tecnos.

BELLO PAREDES, S.A. (2009): «Las autorizaciones administrativas en el ámbito de la energía nuclear: a vueltas con el tema del futuro de la central nuclear de Santa María Garoña», Actualidad Administrativa I9.

BETANCOR RODRÍGUEZ, A. (I994): Las Administraciones independientes: un reto para el Estado social $y$ democrático de Derecho, Madrid: Tecnos.

- (200I): Instituciones de Derecho Ambiental, Madrid: La Ley.

- (2009): Mejorar la regulación. Una guía de razones y medios, Madrid: Fundación Rafael del Pino.

CALDICOTT, H. (2006): Nuclear power is not the answer, New York: News Press.

CODERCH, M. y ALMIRÓN, N. (2008): El espejismo nuclear, por qué la energía nuclear no es la solución sino parte del problema, Barcelona: Los Libros del Lince.

CORRETJER PALOMO, L (i986): «La Comunidad europea de la energía atómica», Gaceta Jurídica de la Comunidad Europea.

DE LA CRUZ FERRER, J. (2009): «El tratamiento jurídico de los residuos radiactivos», en VV.AA., Tratado de Regulación del Sector Eléctrico. Tomo I. Aspectos jurídicos, Cizur Menor: Iberdrola-Aranzadi.

DEL OLMO ALONSO, J. (2002): «Estudio del artículo 244.2 del Real Decreto Legislativo I/1992, de 26 de junio, a la luz del conflicto sobre el almacén de residuos radiactivos de la central nuclear de Trillo I», Revista Jurídica de Castilla-La Mancha 33.

EMMERECHTS, S. (2008): «Environmental Law and Nuclear Law: A Growing Symbiosis», Nuclear Law Bulletin 82.

ENTRENA RUIZ, D. (200I): «El cercenamiento del derecho de acceso de los ciudadanos a la información ambiental, esta vez por el Consejo de Seguridad Nuclear: ¿deben proporcionarse copias de las actas de inspección?», Revista interdisciplinar de Gestión Ambiental 35.

ESTEVE PARDO, J. (2009): El desconcierto del Leviatán. Política y Derecho ante las incertidumbres de la ciencia, Madrid: Marcial Pons.

FORTES MARTÍN, A. (2004): «Delimitación y alcance de la competencia estatal en materia de régimen energético y la competencia autonómica de ordenación del territorio y medio ambiente en la decisión de almacenamiento de residuos nucleares en el territorio de la Comunidad Autónoma», Revista interdisciplinar de gestión ambiental 66.

GARRIBBA, M., CHIRTES, A. y NAUDUZAITE, M. (2009): «The Directive establishing a community Framework for the nuclear safety of nuclear instalations: The EU approach to nuclear safety», Nuclear Law Bulletin 84.

GREENBERG, M.R.: (2009) «NIMBY, CLAMP and the location of new Nuclear-Related-Facilities: U.S. National and II Site-Specific Surveys», Risk Analysis 29 (9).

GÓMEZ CADENAS, J.J. (2009): El ecologista nuclear, Barcelona: Espasa. 
LOPERENA ROTA, D. (20I0): «Las oportunidades de la crisis», en Pernas García, J.J. (Coord.), Medio Ambiente, desarrollo y cooperación internacional. Estudios jurídicos sobre desarrollo sostenible, Cizur Menor: ThomsonAranzadi, p. I7-24.

LÓPEZ CEREZO, J.A. y LUJÁN, J.L. (2000): Ciencia Y Política del Riesgo, Madrid: Alianza.

LÓPEZ RAMÓN, F. (I99I): «El Consejo de Seguridad Nuclear: un ejemplo de Administración independiente», RAP I26.

LOZANO LEYVA, M., (2009): Nucleares, ¿ipor qué no?, Barcelona: Debate.

MARTÍN MATEO, R. (I982): Nuevo Derecho Energético, Madrid: IEAL.

- (I992): Tratado de Derecho Ambiental, Vol. II, Madrid: Trivium.

MARTIN-RETORTILLO BAQUER, L. (I964): Energía nuclear y Derecho: problemas jurídico-administrativos, Madrid: Instituto de Estudios Políticos.

MORALES PLAZA, A. (2003): «El Consejo de Seguridad Nuclear y los riesgos nucleares», Estudios Jurídicos, Abogados del Estado I/2003, p. 49-68.

- (2009a): «El marco regulatorio de la energía nuclear» en VV.AA., Tratado de Regulación del Sector Eléctrico. Tomo I. Aspectos jurídicos, Cizur Menor: Iberdrola-Aranzadi, p. 523-554.

- (2009b): La regulación nuclear globalizada, Madrid: La Ley.

O’HARE, M. (I977): «Not on my block you don't: Facility Siting and the Strategic Importance of Compensation», Public Policy 25/4.

ORTEGA, L. y DE LA SIERRA, S. (Coords.), (2009): Ponderación y Derecho Administrativo, Madrid: Marcial Pons.

PAREJO ALFONSO, L. (2009): «Las relaciones entre el regulador independiente y la Administración», en Serrano González, M. y Bacigalupo Saggese, M. (Directores), Cuestiones actuales del Derecho de la Energía. Regulación, competencia y control judicial, Madrid: Iustel, p. 59-106.

POULEUR, Y. y KRS, P. (2010): «The momentum of the European Directive on Nuclear Safety», Nuclear Law Bulletin 85, p. 5-33.

RAZQUIN LIZARRAGA, J.A. y RUIZ DE APODACA ESPINOSA, A. (2007): Información, participación y acceso a la justicia en materia de medio ambiente. Comentario sistemático a la Ley 27/2006, de 18 de julio, Cizur Menor: Aranzadi.

RODRÍGUEZ DE SANTIAGO, J.M. (2000): La ponderación de bienes y derechos en el Derecho administrativo, Madrid: Marcial Pons.

RUIZ DE APODACA ESPINOSA, A. (2008): «Las condiciones ambientales para las industrias generadoras de energía eléctrica establecidas a nivel comunitario», Noticias de la Unión Europea 284, p. 77-90.

- (2009): «Régimen jurídico de la gestión de los residuos radiactivos», Revista Aranzadi de Derecho Ambiental I4.

- (2009): «El caso de las centrales térmicas de ciclo combinado instaladas en el municipio de Castejón (Navarra): implicaciones jurídico-ambientales», en Loperena D. (director), Conflicto Ambiental, Cizur Menor: Thomsom Reuters-Aranzadi, p. 55-I04.

- (2010a): «Planes energéticos y evaluación ambiental estratégica», Revista Catalana de Dret Ambiental I/20IO, p. I54 .

- (20Iоb): «Gobernanza y riesgo en los procedimientos autorizatorios de instalaciones nucleares», Revista General de Derecho Administrativo 25/2010.

- (20Ir): «Régimen de la energía nuclear a la luz del Derecho Comunitario: competencia, seguridad, aceptación y perspectivas», Noticias de la Unión Europea 322/20II, p. 47-58.

SÁNCHEZ GUITIÁN, M.N. (2006): «Los residuos radiactivos y su desarrollo normativo», en Cremades, J. y Rodríguez-Arana, J. (directores), Derecho de la energía, Madrid: La Ley-Endesa, p. 64I-647.

SANTAMARÍA ARINAS, R.J. (2009): «La reaparición del debate nuclear y el Derecho», en San Martín Segura, D. y Susín Betrán, R. (coords.), Derecho y Política en la Sociedad de Riesgo, La Rioja: Universidad de La Rioja, p. Io3I2O.

SOSA WAGNER, F. (I978): «Localización de centrales nucleares y ordenación urbana», REDA I7, p. 284-289.

SOSA WAGNER, F. y FUERTES, M. (20II): El Estado sin territorio. Cuatro relatos de la España autonómica, Madrid: Fundación Alfonso Martín Escudero-Marcial Pons.

TOCINO BISCAROLASAGA, I. (I975): Riesgo y daño nuclear de las centrales nucleares, Madrid: Junta de Energía Nuclear.

TROMANS, S. (2010): Nuclear Law, Oxford: Hart Publishing. 
WATERLOOS, C. y GALLEGO M. (2007): «El Tratado EURATOM: 50 años al servicio de Europa», Cuadernos de Energía I6. 